\title{
Fragility curves for free and restrained rocking masonry façades in one-sided motion
}

\author{
Linda Giresini1 ${ }^{1, *}$, Claudia Casapulla ${ }^{2}$, Roman Denysiuk ${ }^{3}$, Jose Matos $^{4}$, Mauro Sassu $^{5}$ \\ ${ }^{1}$ Department of Energy, Systems, Territory and Constructions Engineering, University of Pisa, Largo Lucio \\ Lazzarino, 1, 56100, Pisa, Italy; linda.giresini@unipi.it \\ ${ }^{2}$ Department of Structures for Engineering and Architecture, University of Naples Federico II Naples , via \\ Forno Vecchio 36, 80134, Naples, Italy; casacla@unina.it
}

3 ISISE, Department of Civil Engineering, University of Minho, Guimarães, Portugal; roman.denysiuk@algoritmi.uminho.pt

${ }^{4}$ ISISE, Department of Civil Engineering, University of Minho, Guimarães, Portugal; jmatos@civil.uminho.pt

${ }^{5}$ Department of Civil, Environmental Engineering and Architecture, University of Cagliari, Via Marengo 2 09123 Cagliari, Italy; msassu@unica.it

*Corresponding author: linda.giresini@unipi.it; Tel.: +39-0502218204

\begin{abstract}
This paper deals with the need of extending results of deterministic rocking analyses to stochastic analyses on restrained masonry façades in one-sided motion. The purpose is to define the level of improvement achieved with any anti-seismic device of a given stiffness and strength, in terms of reduction of probability of exceedance of a certain limit state. The most efficient intensity measures (IMs) are identified for three masonry façades of churches in free and restrained conditions. A reliability analysis is carried out by considering over 70 earthquakes, of which 50 recorded during the recent 2016-2017 Central Italy Earthquake. Four limit states are taken into account: rocking initiation, limited rocking, moderate rocking and near-collapse condition. The yielding limit state is considered for the analysis with anti-seismic devices. Univariate and bivariate fragility curves (FCs) are compared in free and restrained configurations, to discuss the reduction of probability of exceedance depending on 15 intensity measures. The results show that the best IMs are velocity-based parameters, in particular the Fajfar Index and Peak Ground Velocity, together with Peak Ground Acceleration. In one-sided motion without restraints, the higher the compression stiffness of the sidewalls, the more unstable the wall is in probabilistic terms. Practical curves show, for each IM, the reduction of probability of exceedance obtained thanks to assumed horizontal restraints. These help to understand, in a stochastic perspective, to what extent the anti-seismic device can be beneficial or detrimental (in case of amplifications of motion) for given earthquake intensities. The comparison of univariate and bivariate FCs confirms the superiority of bivariate FCs. Indeed, often the univariate curves sensitively underestimate the probability of exceedance, especially for low-medium intensity earthquakes, and are not able to offer any information regarding the influence of other IMs.
\end{abstract}

KEYWORDS: rocking; one-sided motion; fragility curves; horizontal restraints; masonry façades; intensity measures 


\section{INTRODUCTION}

The out-of-plane behavior of masonry walls involves the rocking motion of rigid blocks, considered as single (SDOF) or multi (MDOF) degree-of-freedom systems. The possible tools currently used to assess their seismic vulnerability are deeply discussed in [1], [2], covering force-based, displacement-based, standard and rocking approaches. These procedures can be adopted to evaluate the behavior of many types of structural and nonstructural elements such as parapets, gable ends, chimneys and masonry walls, often struck by earthquakes [3], [4]. Observations on past earthquakes occurred in New Zealand [5] showed that the majority of parapets that exhibited no damage were properly restrained to limit out-of-plane. The risk associated to these mechanism is relevant, not only for the safeguard of human life, but also for adjacent structures. Indeed, from the observations sometimes the only damage to a structure was the fall of chimneys or parapets onto or through the roof of a parapet or neighboring building [5]. Other observations regarded masonry façades of churches damaged by the 2011 Christchurch Earthquake [6] and by the 2012 Emilia Romagna Earthquake [7]. Numerous uncertainties affect the MDOF models, such as the energy dissipation during each impact or the boundary conditions to assume. In order to stochastically assess the influence of anti-seismic devices, it is necessary to simplify the topic as much as possible. For instance, the incipient overturning of a masonry wall may be considered by assuming a SDOF rigid block rotating around a base hinge [8]. However, also the rocking motion of a SDOF block is strongly influenced by the restitution coefficient, related to the dissipative properties, and by the boundary conditions [9], [10]. The first issue, although, in principle, extremely relevant is here neglected since the comparison is made between free and restrained conditions assuming for them the same restitution coefficients, the analytical one [11]. In a more realistic analysis, experimental values of restitution coefficients should be taken into account. For this purpose, several experimental tests on masonry walls confirm that generally the real value is about $90 \%$ of that analytical [12], [13]. In this sense, the performed analyses are on the safe side, as a higher restitution coefficient generally implies larger rotation amplitudes. Moreover, the type of input motion plays a crucial role in the dynamic response. The earthquake that causes motion is characterized by many parameters, all of them affecting the output in a combined way. As a consequence, it is relevant to identify the most meaningful parameters to consider when the stability of the block has to be assessed.

These issues are commonly addressed by using deterministic or probabilistic approaches [1]. Based on the integration of the equation of motion, the former is generally aimed at defining the peak value of the motion amplitude that defines the stability of the block, given its deterministic geometric parameters and the type of excitation. Traditional deterministic approaches are those proposed by Makris and Konstantinidis [14], that introduced rocking spectrum as a distinct and valuable intensity measure of earthquakes. Other deterministic approaches are based on the identification of the worst input scenario corresponding to the resonant response of the rigid blocks [15]-[21]. In this line, Casapulla et al. [15], [21] and Casapulla [17] proposed a simplified representation of the seismic input as a superposition of two sequences of instantaneous Dirac impulses of acceleration and identified the resonant condition with a time interval between the main impulses coincident with the amplitude-dependent durations of the half-cycles of the motion. DeJong [22] defined a theoretical accelerogram with the condition of maximization of the input energy, dealing with a step function with alternate sign, always opposite to the current rotational velocity of the block. Alongside these studies, the probabilistic approaches attracted increasing attention over the last years. These procedures started to be applied in seismic field almost twenty years ago, with the introduction of the concept of fragility, or conditional probability of failure [23]. Sorrentino et al. [24] numerically investigated how the parameters of real seismic records (Peak Ground Acceleration, PGA, Peak Ground Velocity, PGV, Peak Ground Displacement, PGD, mechanical energy, etc) are meaningful in defining the seismic hazard of a free rocking block. They stated that PGV is the most significant parameter as it takes into account both amplitude and frequency. Referring to fragility applied to rocking, Dimitrakopoulos and Paraskeva [25] investigated the response of rocking structures to near-fault seismic actions and highlighted the most important Intensity Measures (IMs) 
characterizing the rocking response and the relevance of bivariate fragility curves. PGA and Peak Total Roof Velocity (PTRV) were assumed as intensity measures in the determination of damage fragility functions for parapets and rooftop chimneys [26]. Other authors performed a seismic reliability assessment of classical columns, by using synthetic or recorded ground motions [27], [28]. Generally, the adopted Engineering Demand Parameter (EDP) is the maximum amplitude ratio, whereas the peak ground velocity is one of the most reliable IMs [25]. Performance levels can then be assigned to each EDP, together with the values of the corresponding thresholds, to generate fragility curves. Therefore, these tools are more reliable than a simple deterministic analysis, mainly for the extremely high sensitivity of the response to the input motion.

In this paper, the stochastic approach is adopted to define fragility curves of masonry walls regarded as rigid blocks under one-sided rocking motion. The probability of exceedance of specific limit states in the rocking response is calculated when the walls are both in free conditions and in restrained conditions. The latter situation refers to the state of the walls strengthened by proper anti-seismic devices simulated by horizontal springs. These springs can reproduce the common steel tie-rods usually adopted as strengthening techniques for impeding or limiting the out-of-plane behavior of masonry structures. Three masonry façades of churches, struck by the 2016-17 Central Italy Earthquake, are considered as case studies. To calculate the structural reliability, there is the need of computing first the structural failure and then the failure probability. The structural failure is estimated by performing non-linear transient analyses that evaluate whether the EDP has been exceeded. The calculation is made for over 70 earthquakes, each of them defined by $15 \mathrm{IMs}$. On the other hand, the structural reliability is estimated by determining the failure probability associated to limit states that define safe and unsafe domains. Four limit states are taken into account for one-sided rocking without restraints: rocking initiation, limited rocking, moderate rocking and near-collapse condition. For one-sided rocking with restraints, only rocking initiation and limited rocking corresponding to yielding of the steel tierod are significant and therefore considered. The basic scheme of the structural rocking system and the three façades are presented in Section 2. The reliability analysis is illustrated in Section 3, introducing the seismic input parameters and the IMs. Section 4 discusses the correlation between EDP and IMs by analyzing Pearson's and Spearman's coefficients. Afterwards, univariate and bivariate fragility curves are obtained for the case with and without horizontal restraints acting as anti-seismic devices, and the resulting curves are compared (Section 5,6). Such comparison allows quantitatively assessing the seismic improvement achieved with the anti-seismic devices in a stochastic perspective.

\section{STRUCTURAL ASSESSMENT}

\subsection{Rocking analysis for one-sided motion of free and restrained walls}

The considered model is a rectangular block of mass $m$ rocking around $\mathrm{O}$ or $\mathrm{O}$ ' (Figure 1), defined in size by a semi-diagonal $R$ that connects the center of mass to the pivot point, and in shape by the slenderness ratio $\alpha$, arctangent of the ratio thickness $s$ to height $h$ (Figure 1a). The boundary conditions in the rocking motion are relevant as they strongly influence the dynamic response [29]-[31]. The sidewalls (or transverse walls) can be modelled as spring bed with specific stiffness per unit of length. When the masonry façade rotates inward, it impacts the sidewalls (Figure 1a). In this case, a compression stiffness has to be considered. When the wall rocks outward and is not restrained by any device, a spring bed in tension should be taken into account. Being masonry poorly resistant in tension, in this work the spring bed is supposed to be active only in compression, and its compression stiffness is [9]:

$$
K_{\text {compr }}=\frac{\mathrm{E}_{\mathrm{x}} \mathrm{A}}{\mathrm{L} \bar{h}}=\mathrm{E}_{\mathrm{x}} \frac{\mathrm{t}}{\mathrm{L}}
$$


where $\mathrm{E}_{\mathrm{x}}$ is the masonry elastic modulus in horizontal direction, $\mathrm{t}$ and $\bar{h}$ respectively thickness and effective depth of the transverse walls, whereas $\mathrm{A}=\mathrm{t} \bar{h}$ is the side walls cross section. This condition is called one-sided (1S) motion. When the spring bed can be assumed to act in tension, the stiffness to consider is related to the dissipated energy due to friction in the sidewalls [32]. The restrained configuration is that where steel-tie rods tend to recenter the wall in outward motion. The steel tie-rods, modelled as individual springs (b), are supposed to be active only in tension (Figure 1b).

The full equation of motion of the non-smooth contact problem is [9]:

$$
\begin{aligned}
& I_{0} \ddot{\vartheta}+\operatorname{sgn}(\vartheta) m g R \sin A_{\vartheta}+ \\
& \begin{array}{l}
+\operatorname{sgn}(\vartheta) K \beta^{2} R^{2} \cos A_{r, \vartheta}\left[\sin \alpha_{r}-\sin A_{r, \vartheta}\right]+\operatorname{sgn}(\vartheta) K_{c o m p r} \bar{h}\left(A+\frac{B \bar{h}}{2}+\frac{C \bar{h}^{2}}{3}\right) \\
\quad-m \ddot{u}_{g} R \cos A_{\vartheta}=0
\end{array}
\end{aligned}
$$

where $A_{\vartheta}=\alpha-\operatorname{sgn}(\vartheta) \vartheta$ and $A_{r, \vartheta}=\alpha_{r}-\operatorname{sgn}(\vartheta) \vartheta . I_{0}$ is the polar inertia moment with respect to the oscillation line O'-O, $I_{0}=\frac{4}{3} \mathrm{~m}\left(\mathrm{~h}^{2}+\mathrm{s}^{2}\right)=\frac{4}{3} \mathrm{mR}^{2}$, for perpendicular blocks. However, inertia moments have to be calculated from the real geometry of the actual masonry façade. $\alpha_{r}$ is the single spring radius vector and $\beta$ defines the single spring position (2.2). The terms multiplied by $K_{\text {compr }}$ are [9]:

$A=\operatorname{sgn}(\vartheta) s^{2} \sin \vartheta \cos \vartheta(1-\cos \vartheta)$

$B=s\left(\sin ^{2} \vartheta \cos \vartheta-\cos ^{3} \vartheta+\cos ^{2} \vartheta\right)$

$C=\operatorname{sgn}(\vartheta) \sin \vartheta \cos ^{2} \vartheta$

$\ddot{u}_{g}$ is the acceleration time-history (in gravity acceleration $g$ units), which can be artificially generated or recorded. This work considers only natural seismic records, as specified in $\S 3.3$. During each impact, that is for $\vartheta=0$, the velocity after impact $\dot{\vartheta}^{+}$is assumed as the velocity before impact $\dot{\vartheta}^{-}$reduced by a restitution coefficient $e$ :

$$
\dot{\vartheta}^{+}=\mathrm{e} \dot{\vartheta}^{-}
$$

The restitution coefficient defined by Housner [11] for rectangular block is function of the slenderness ratio $\alpha$ :

$$
e=1-\frac{3}{2} \sin ^{2} \alpha
$$

This theoretical value in real conditions, e.g. for masonry walls, should be generally reduced for considering larger dissipation due to non-perfect conditions of the base hinge, generally a mortar layer. A reduction by 80 $90 \%$ was generally obtained for common masonry parapets [12], [33], [34]. However, in this work such a reduction does not apply, to get results in favor of safety and to simplify the assumptions made. Moreover, as the façades have been associated to rectangular blocks (2.3), the analytical expression of restitution coefficient is assumed in the calculations. 


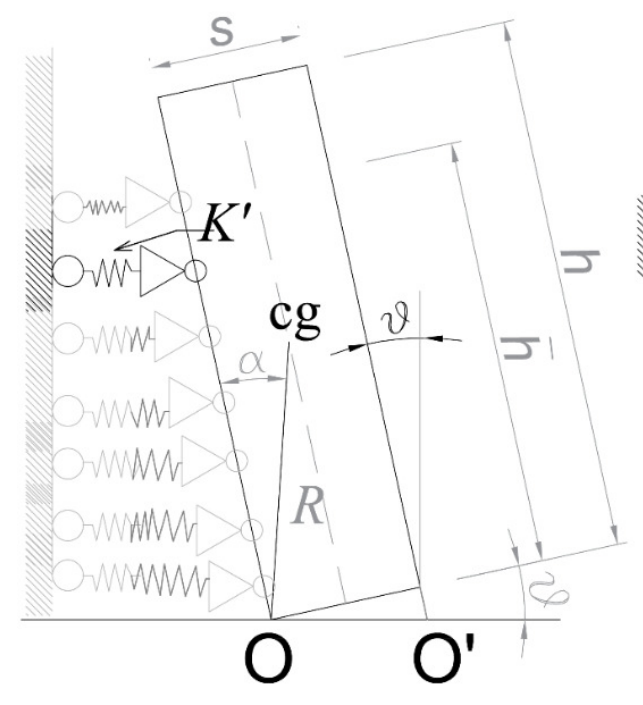

(a)

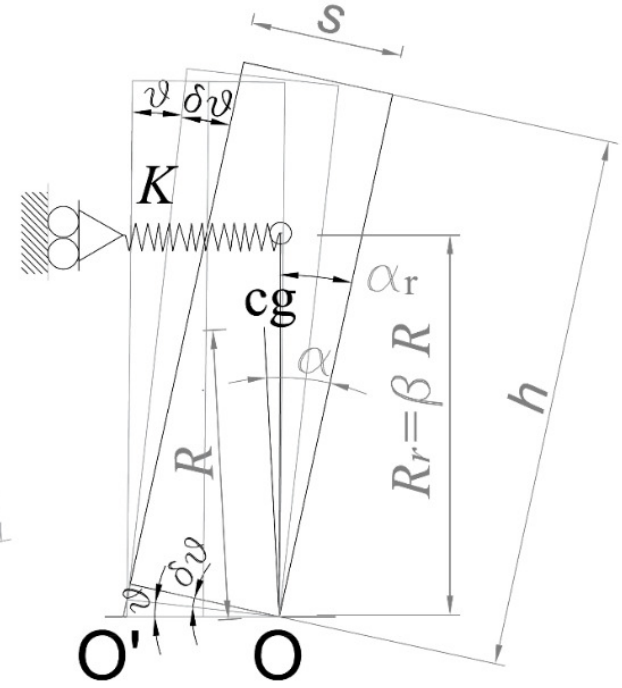

(b)

Figure 1. Rocking block assumed in the physical model for a masonry façade: inward rotation, wall impacts sidewalls, one-sided motion (a); outward rotation, tie-rods restraint the wall (b).

The analysis results, obtained from a specifically developed MATLAB code, are expressed in terms of normalized rotation $\vartheta / \alpha$ time-histories. The code uses a $4^{\text {th }}-5^{\text {th }}$ order Runge-Kutta integration technique. The maximum value of the normalized rotation time-history represents the individual output or realization, taken as engineering demand parameter, for each earthquake. Afterwards, the results are filtered by the performance criteria related to the limit states defined in $\S 2.2$ and further processed in the reliability analysis step.

\subsection{Performance criteria and limit states}

The assumed performance criteria define four possible limit states for wall without restraints: rocking initiation, limited rocking, moderate rocking and near-collapse condition (Table 1). For the restrained wall, only rocking initiation and yielding limit can be considered. The second one, LSY, corresponds to yielding of the steel tie-rod. Although the displacement capacity of a steel tie-rod can be higher, this limit state is taken into account because, after plasticization, the modelling of the tie in the return phase would be problematic. Indeed, stress concentration in masonry or tie buckling could occur: these aspects are complex to be included in a simplified formulation and out of the scope of the present work. Each limit state is identified by an engineering demand parameter EDP, taken as the maximum normalized rotation value $\vartheta_{\text {max }} / \alpha$. The rocking initiation $L S 0$ corresponds to a value of rotation different from zero. For this case, a straightforward check can assess whether the rocking initiates or not. Indeed, the uplift occurs when the peak ground acceleration is greater than the minimum acceleration that causes rocking, $\ddot{u}_{g, \min }=\tan \alpha$. Otherwise, the structure remains at rest. All the considered records cause the rocking initiation and therefore the fragility curves are trivial and not reported for this limit state. The limited rocking $L S 1$ is a limit state for which the maximum normalized rotation attains a value of 0.10 . This value, where rotation is an order of magnitude smaller than the slenderness ratio, is considered by Dimitrakopoulos et al. [25] as a promising balance of the benefits of rocking isolation, without relevant risk of overturning. Limit state $L S 2$ is called moderate rocking $\left(\left(\vartheta_{\max } / \alpha\right)_{\lim }=0.4\right)$ and it is contemplated as most of the considered earthquakes have a high number of normalized rotations values around it. This occurs also for other seismic records when the rocking motion of a masonry façade is analyzed [31]. Limit state $L S 3$ corresponds to a near-collapse condition, for which it is assumed $\left(\vartheta_{\max } / \alpha\right)_{\text {lim }}=1.5$. A wall 
can be stable even when $\vartheta_{\max } / \alpha>1$, up to $\frac{\vartheta_{\max }}{\alpha}=\frac{\pi}{2 \alpha}$. This differentiates the rocking block from a SDOF oscillator in kinematic approach based on the limit analysis, where the threshold for stability is $\frac{\vartheta_{\max }}{\alpha}=1$ [29]. The limit states $L S 1, L S Y$ and $L S 2$ can be seen as serviceability limit states, whereas $L S 3$ is an ultimate limit state. Theoretically, the maximum rotation is $\vartheta_{\max }=\pi / 2$ : a sixth limit state, corresponding to overturning, could be therefore investigated. In this case, structural fragility must be defined referring to a categorical problem, by properly modifying the way to calculated the collapse probability [25]. However, since before overturning the collapse mechanisms of masonry walls involve other phenomena, e.g. material crumbling, this limit state is not considered in this work. To summarize, all the limit states of Table 1 are considered for the one-sided (1S) free motion, whereas only LS0 and LSY are analyzed for the one-sided restraint motion (1S+K), as the values of normalized rotations greater than those corresponding to yielding are meaningless.

Table 1 Limit states defined in the reliability analysis of rocking walls.

$$
\text { EDP }=\left(\vartheta_{\max } / \alpha\right)_{\text {lim }} \quad \text { Definition } \quad \text { Structural behavior }
$$

Limit State LS

\begin{tabular}{cccc}
\hline$L S 0$ & 0.0 & rocking initiation & Uplift \\
\hline$L S Y^{*}$ & Depending on geometry & tie-yielding & Yielding of the tie-rods \\
\hline$L S 1$ & 0.1 & limited rocking & Minor damages \\
\hline$L S 2$ & 0.4 & moderate rocking & $\begin{array}{c}\text { Larger damages and } \\
\text { influence on the adjacent } \\
\text { structures (e.g. floors) }\end{array}$ \\
\hline$L S 3$ & 1.5 & Near collapse & Overturning
\end{tabular}

*The unique one considered for the restrained configuration.

\subsection{Application of rocking on real cases}

The examined rocking structures are three masonry façades struck by the 2016-17 Central Italy Earthquake. Because the most of the considered seismic records belong to this event, three real cases of masonry façades have been investigated. They are the main façades of the San Michele Arcangelo church in Lisciano (municipality of Ascoli Piceno), the Santa Maria in Via's church and the San Filippo Neri church in Camerino (municipality of Macerata), all in the Marche Italian region (Figure 2). From now on, they will be respectively called LSCH, SMVCH, SFILCH. These examples are chosen as representative of typical church typologies: LSCH is a single nave church, whereas SMVCH and SFILCH are an elliptical and a three-nave churches with greater dimensions (Figure 3). The main façade of LSCH is slender and is not restrained by any tie-rods, while in SMVCH the façade is strengthened by two tie-rods (Figure 2c) of diameter $20 \mathrm{~mm}$, at depth $15 \mathrm{~m}$ from the base and have length of $5.3 \mathrm{~m}$. LSCH exhibits a clear incipient overturning of the main façade detached from the sidewalls, whereas the rocking part of SMVCH involves a small part of the sidewalls. SFILCH's façade underwent complete overturning of the upper part of the façade: the horizontal hinge is located at about $14 \mathrm{~m}$ from the ground (Figure 2g). The seismic records should be applied in the analysis of SFILCH after a filtering process, to consider the vibration effects of the substructure. However, the records are assumed as provided by the database without any modification for the sake of comparison (§ 3.3$)$. 
Table 2 reports the geometric and mechanical parameters needed for rocking analysis. The three façades are not in principle rectangular, but they have been associated to a rectangular shape by calculating the radius vector, which connects the pivot points to the actual center of mass, from the inertia moments. It is important to notice that the inertia moments are obtained by considering the actual geometry of each façade. Once the radius vector is known, it is straightforward to calculate the equivalent height of the rectangular rocking block. LSCH and SMVCH have similar slenderness but the latter has the highest inertia moment. SFILCH has the smallest size (radius vector) and inertia moment, but the highest slenderness. In one-sided (1S) motion without restraints, the spring bed stiffness is considered in compression, and calculated from Eq. (1) for each façade. As shown in Figure 3, SMVCH has four side walls, whereas SFILCH (similarly to LSCH, not displayed) has two side walls. Being the spring beds in parallel, the stiffness per unit of length of each sidewall is summed up to obtain the values reported in Table 2 .

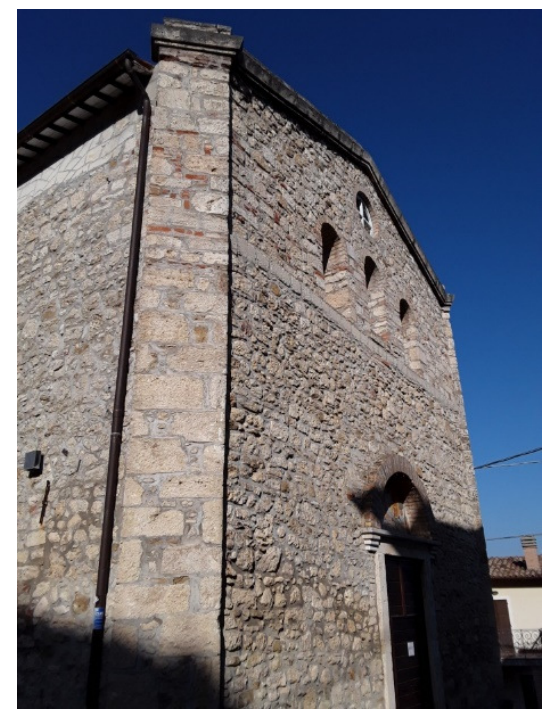

(a)

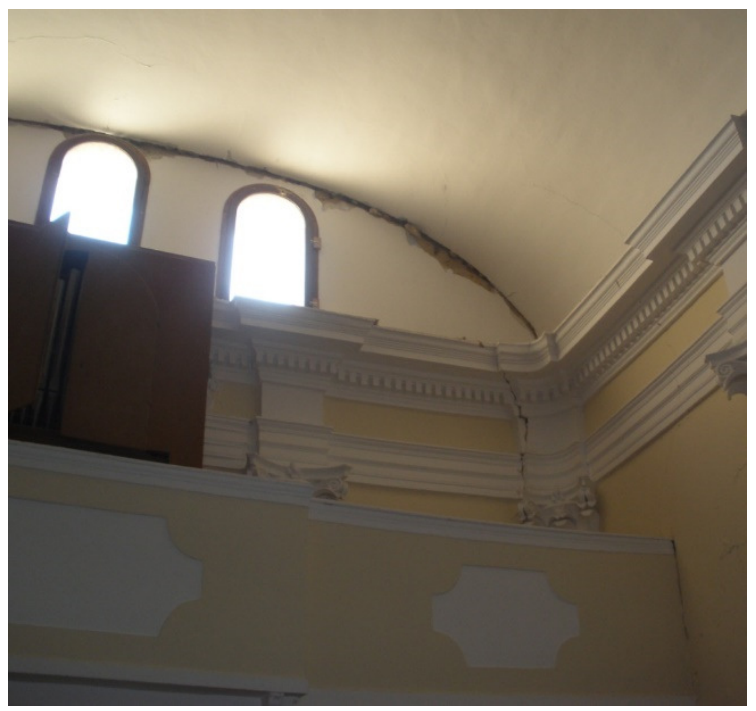

(b) 


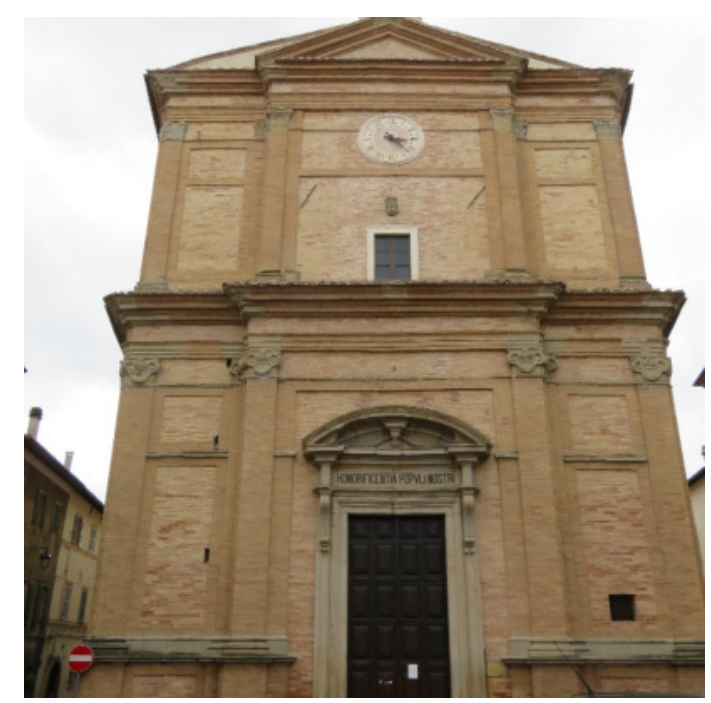

(c)

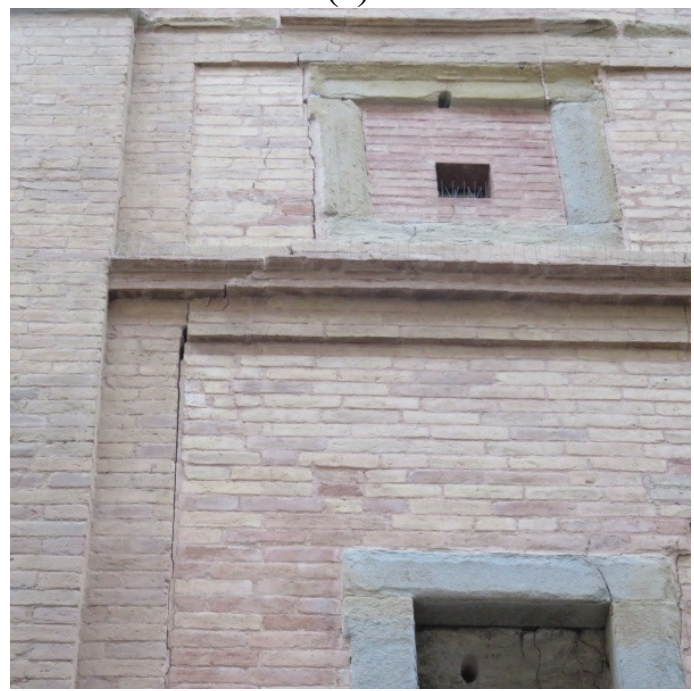

(e)

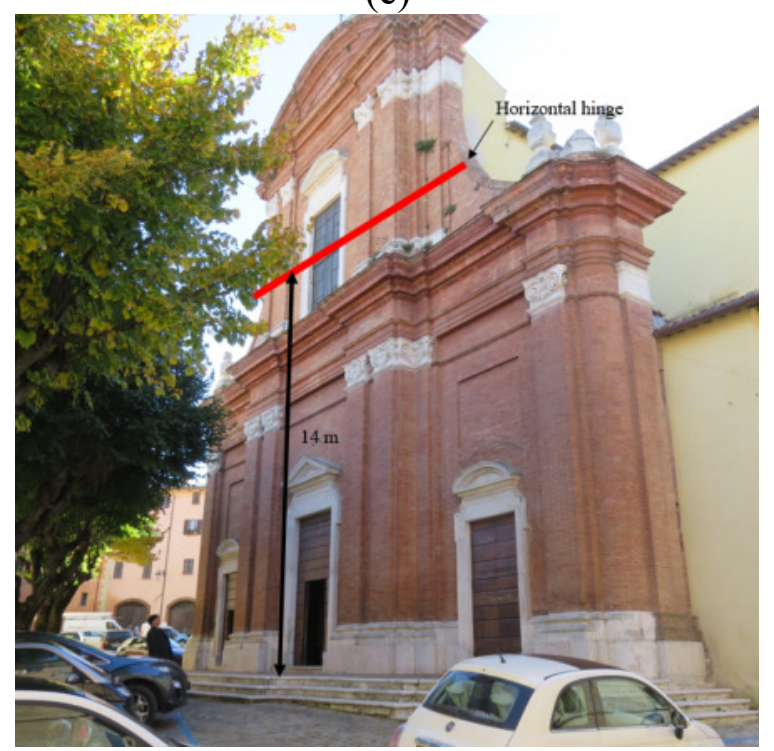

(g)

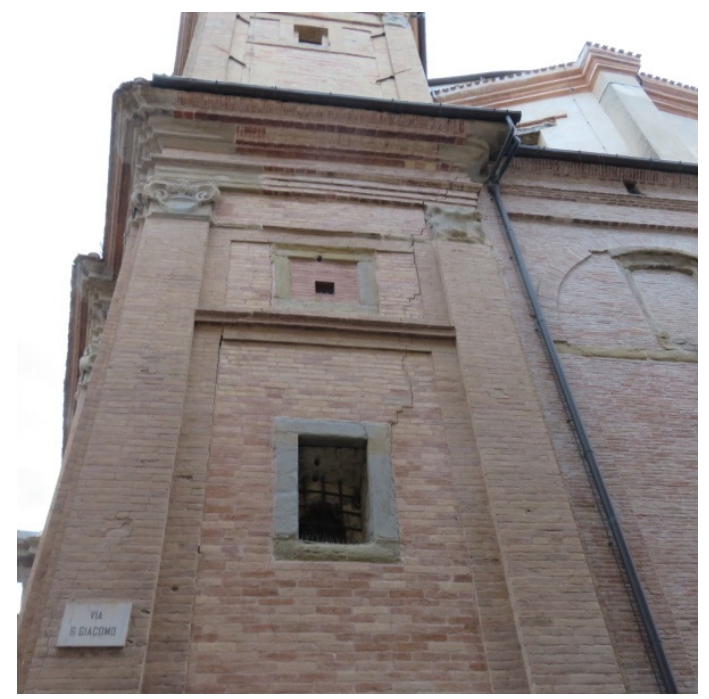

(d)

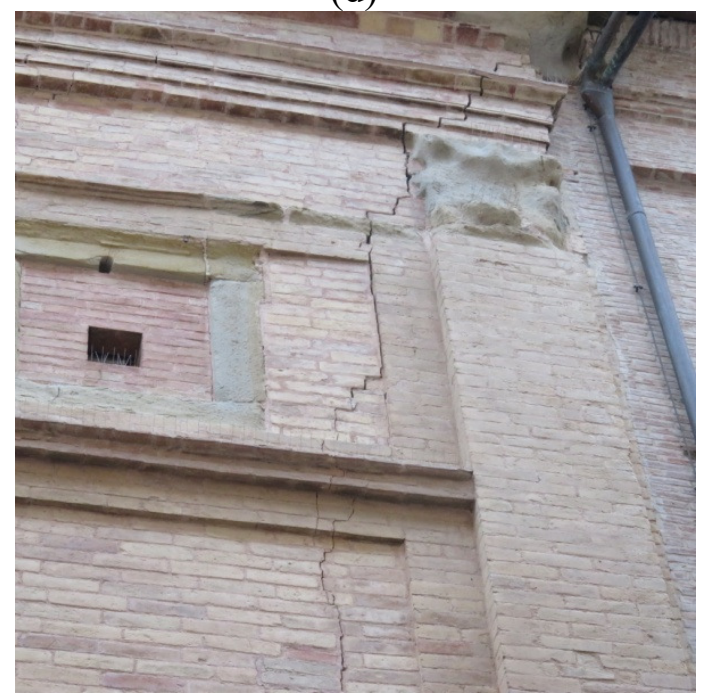

(f)

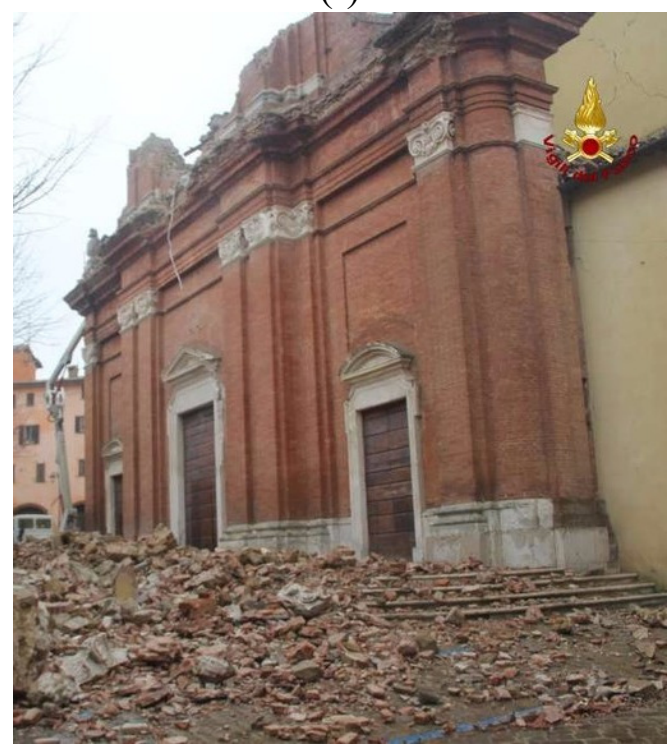

(h)

Figure 2. San Michele Arcangelo church (LSCH) in Ascoli Piceno: main façade (a) and internal view of the incipient overturning (b); Santa Maria in Via's church (SMVCH) in Camerino (Macerata): main façade (c), view of the side part from North (d) and zoom magnifications on the cracks (e, f); San Filippo's church (SFILCH) in Camerino (Macerata): main façade before $(\mathrm{g})$ and after $(\mathrm{h})$ collapse. 
Table 2 Geometric and mechanical parameters for the rocking analysis of the church façades.

\begin{tabular}{|c|c|c|c|c|c|c|c|c|}
\hline $\begin{array}{l}\text { Rocking } \\
\text { façade }\end{array}$ & $\begin{array}{l}\text { Equiv. } \\
\text { height } \\
{[\mathrm{m}]}\end{array}$ & $\begin{array}{c}\text { Thickness } \\
{[\mathrm{m}]}\end{array}$ & $\begin{array}{c}\text { Width } \\
{[\mathrm{m}]}\end{array}$ & $\begin{array}{c}\text { Specific } \\
\text { weight } \\
{\left[\mathrm{kN} / \mathrm{m}^{3}\right]}\end{array}$ & $\mathrm{R}[\mathrm{m}]$ & $\begin{array}{c}\alpha \\
{[\mathrm{rad}]}\end{array}$ & $\begin{array}{c}\mathrm{I}_{0} \\
{\left[\mathrm{~m}^{4}\right]}\end{array}$ & $\begin{array}{l}\mathrm{K}_{\text {compr }} \\
{\left[\mathrm{N} / \mathrm{m}^{2}\right]}\end{array}$ \\
\hline LSCH & 8.85 & 0.65 & 9.30 & 21.00 & 4.44 & 0.07 & $2.82 \mathrm{E}+06$ & $8.08 \mathrm{E} 8$ \\
\hline SMVCH & 21.30 & 1.30 & 15.50 & 18.00 & 10.67 & 0.06 & $1.27 \mathrm{E}+08$ & $2.04 \mathrm{E} 9$ \\
\hline SFILCH & 7.64 & 0.80 & 12.00 & 18.00 & 3.84 & 0.10 & $2.36 \mathrm{E}+06$ & $7.50 \mathrm{E} 8$ \\
\hline
\end{tabular}

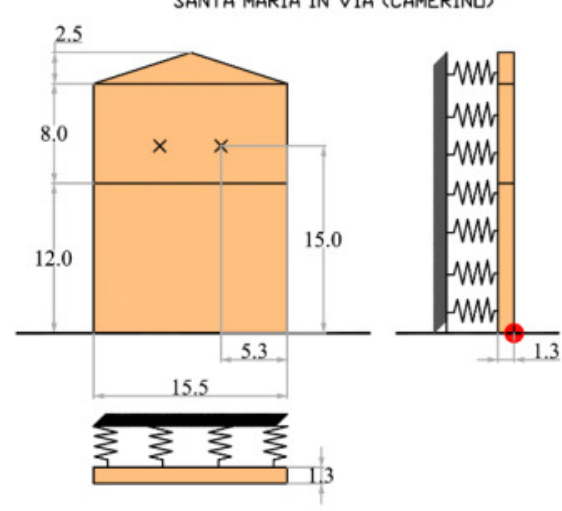

(a)

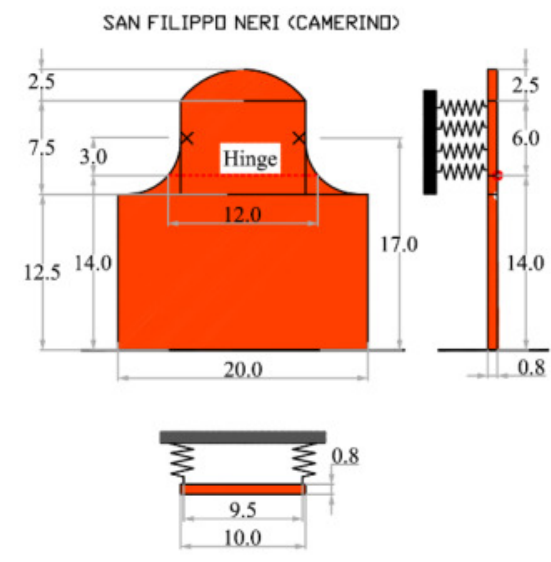

(b)
SAN MICHELE ARCANGELQ (LISCIAND)

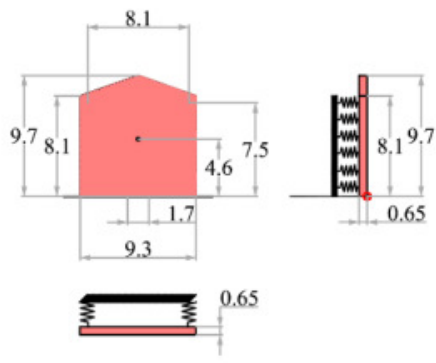

(c)

Figure 3. Santa Maria in Via church (SMVCH, a), San Filippo church (SFILCH, b), San Michele Arcangelo (LSCH, c): geometric dimensions (m) and spring bed configuration representing sidewalls.

\subsection{Definition of steel tie-rods as horizontal restraints}

The use of anti-seismic devices as stabilizing elements helps to reduce the rotation amplitude in the dynamic behavior, generally making the response safer. Such anti-seismic devices, e.g. steel tie-rods, may be modelled through concentrated springs with stiffness $\mathrm{K}$ at a specific depth of the wall (Figure 1b):

$$
R_{r}=\beta R \text {. }
$$

$\beta$ is a dimensionless coefficient that defines the position of the spring with respect to the semi-diagonal $R$. Let us assume that the block is enough slender to consider the spring in the middle plane of the wall. The rocking analysis are performed by considering two main configurations. When the wall is free, namely is not restrained by any device, the value of $K$ in Equation (2) (Figure 1a) equals zero and $K_{\text {compr }}$ assumes a finite value. By contrast, if the wall is strengthened by some stabilizing restraint, the value of $K$ is different from zero and $K_{\text {compr }}$ equals zero (Figure $\left.1 b\right) . K_{\text {compr }}$ values are reported in Table 2.

The stiffness $K$ of the horizontal restraint is taken as the actual one only for SMVCH, since in this church the steel tie-rods are present (Figure 3a). Instead, for LSCH and SFILCH the stiffness is obtained with a design procedure. In particular, the PGAs are assumed according to the Italian Technical Rules for constructions [35], [36] as $1.8 \mathrm{~m} / \mathrm{s}^{2}$ and $2 \mathrm{~m} / \mathrm{s}^{2}$ for LSCH and SFILCH, respectively. By considering type A soil with soil factor $S$ $=1.5$, behavior factor $q=2$ and confidence factor $F_{\mathrm{C}}=1.35$ (corresponding to the poorest knowledge level), the seismic demands in terms of spectral accelerations for SLV (safeguard of life limit state) respectively are $1.35 \mathrm{~m} / \mathrm{s}^{2}$ and $1.9 \mathrm{~m} / \mathrm{s}^{2}$ also taking into account for SFILCH the position of the rocking wall at a certain height from the ground. The rotational equilibrium around the cylindrical hinge is satisfied by yielding forces of two 
tie-rods of $82.4 \mathrm{kN}$ for LSCH and $217.7 \mathrm{kN}$ for SFILCH, which imply the corresponding mechanical and geometrical parameters shown in Table 3. Once the steel elastic modulus $E$, the section of the tie-rod $A=\frac{\pi D^{2}}{4}$ and its length $L_{t i e}$ are known, the stiffness of the steel tie-rods is simply given by:

$$
K=\frac{E A}{L_{t i e}}
$$

Table 3 Definition of the stiffness of the steel tie-rods

\begin{tabular}{ccccccc}
\multicolumn{1}{c}{$\begin{array}{c}\text { n. of } \\
\text { tie- } \\
\text { Rocking façade }\end{array}$} & PGA [m/s $\left.{ }^{2}\right]$ & rods & Tie diameter $[\mathrm{mm}]$ & Tie length $[\mathrm{m}]$ & Height from the rocking hinge [m] & K [N/m] \\
\hline LSCH & 1.8 & 2 & 16 & 4.5 & 7.5 & $1.88 \mathrm{E}+07$ \\
\hline SMVCH & - & 2 & 20 & 6 & 15 & $2.20 \mathrm{E}+07$ \\
\hline SFILCH & 2.0 & 2 & 26 & 8.5 & 3 & $2.56 \mathrm{E}+07$
\end{tabular}

\section{RELIABILITY ANALYSIS}

\subsection{Structural fragility definition}

The structural reliability is assessed through the definition of fragility (or vulnerability) as conditional probability of failure. The issue requires clearly defining the engineering demand parameter EDP and the Intensity Measure IM that describes the input acceleration history $\ddot{u}_{g}$ (Equation (2)). The EDP is the simplest output coming from the analysis, namely the maximum normalized rotation, whereas the IMs is the intensity measure describing the inputs. For a detailed description of this latter point the reader is referred to $\S 0$. The fragility is defined after a conditional probability that the EDP goes beyond a capacity limit $C$, given an $I M$ associated to the input action:

$$
P_{c}=P(E D P>C \mid I M) \text {. }
$$

The capacity threshold is connected to the limit states defined in $\S 2.2$. It is assumed that rocking occurs for each earthquake or, in other words, that the limit state $L S O$ is always exceeded to obtain significant results from the analysis. The fragility analysis is performed by following the procedure suggested by Padgett et al. [37], briefly described below. The conditional probability is expressed for the serviceability and ultimate limit states with the standard cumulative distribution function $\Phi$ :

$$
P_{C}=\Phi\left(\frac{\ln S_{D}-\ln C}{\beta_{D \mid I M}}\right)
$$

where $S_{D}$ is the median structural demand (that is $E D P$ ) while $C$ is the capacity related to the limit states. $\beta_{D \mid I M}$ is the logarithmic standard deviation, or dispersion, of the demand conditioned on the $I M$ level. Only demand uncertainties are taken into account. A power model describes the relationship between $S_{D}$ and IM for the definition of the univariate (conventional) fragility curves:

$$
S_{D}=a I M^{b} .
$$

A linear regression of the logarithmic allows calculating, for each $I M$ level, the regression coefficients $a$ and $b$. Therefore, the natural logarithm of the median structural demand is expressed as: 


$$
\ln S_{D}=\ln a+b \ln I M .
$$

In addition, bivariate fragility curves can be obtained, by expliciting the structural demand as:

$$
S_{D}=a I M_{1}^{b_{1}} \cdot I M_{2}^{b_{2}} .
$$

Similarly to what done for univariate analysis, a multi-linear regression allows computing the regression coefficients $a, b_{1}$ and $b_{2}$ that define the generic equation of a plane in the three dimensional space $\ln I M_{1}$, $\ln I M_{2}$ and $\ln a$ :

$$
\ln S_{D}=\ln a+b_{1} \ln I M_{1}+b_{2} \ln I M_{2} .
$$

Once that the median structural demand $S_{D}$ is calculated, Equation (8) applies to find the conditional probability of failure and therefore the bivariate fragility curve.

\subsection{Definition of seismic input parameters}

In the definition of a probabilistic method to apply to rocking structures, there is the need to generalize the concept of using significant ground motions. Most of the time, the acceleration time history has randomly distributed spikes and there are not distinct pulses that could largely simplify the issue. Moreover, even when more than one distinguishable pulses are contained in an earthquake record, it is challenging to define the procedure of incorporating their features in a single time scale [38]. The input function is described by numerous ground motion parameters, which can be either dependent or independent on the response. The ground motion parameters may be related to time-history, to energy content or to spectral components. Classical ground motion parameters related to time history are PGV (Peak Ground Velocity), PGA (Peak Ground Acceleration), PGD (Peak Ground Displacement). Sometimes, further parameters derived from the acceleration and velocity time history are considered: the third highest peak of acceleration, the third highest peak of velocity and the acceleration peak after filtering frequencies higher than $9 \mathrm{~Hz}$ [28]. In this paper, the ratio of PGV and PGA is considered to take into account the effects of both PGA and PGV. The spectrum intensity $S I_{H}$, defined after Housner, is a spectrum-based parameter defined as the area under the elastic velocity spectrum between the periods $T 0.1$ and 2.5 seconds. That range was considered by Housner the vibration period range of interest for civil buildings. The damping coefficient $\xi$ associated to the spectrum is taken equal to 0.05. Other acceleration-based parameters are the Arias intensity, $I_{a}$, and the root-mean-square acceleration, RMSA, that better describe the short period structures [38]. By contrast, velocity-based parameters, including PGV, such as the spectrum intensity, $S I_{H}$, and the Fajfar [39] index, $I_{F}$, better describe the response of intermediate and long period structures. The significant strong motion duration $t_{D}$ is defined according to [40]. $t_{D}$ is based on that part of the recorded strong ground motion that generates 90 per cent of the overall acceleration, velocity, and displacement spectral amplitudes. The duration can be then expressed by $t_{D}=t_{95}-t_{5}$ where $t_{95}$ and $t_{5}$ are respectively the times where $95 \%$ and $5 \%$ of Arias intensity is reached.

For what concerns frequency parameters, the mean period $T_{m}$, derived from Fourier spectra [41], was shown to be one of the best ones when no distinguishable pulses can be identified in the seismic record. Another relevant parameter, depending on it, is the characteristic length scale of the ground excitation. This parameter, expressed by $L_{m}=T_{m}^{2} \cdot P G A$ [38], gives a measure of the persistence of the most energetic pulse capable to generate inelastic deformation. Moreover, the cumulative absolute velocity CAV can be considered as the sum of the consecutive peak-to-valley distances in the velocity time history and was shown to well express the destructive potential of an excitation [42]. 
Table 4 - Intensity measures used for fragility curves. $a(t)$ acceleration time-history in units of $\mathrm{g}, v(t)$ velocity time-history, $u(t)$ displacement time-history, $t_{E}$ duration of the seismic record.

\begin{tabular}{|c|c|c|c|}
\hline Intensity measure & Description & Expression & $\begin{array}{l}\text { Literature } \\
\text { reference }\end{array}$ \\
\hline PGA & Peak Ground Acceleration & $P G A=\max |a(t)|$ & {$[25]$} \\
\hline PGV & Peak Ground Velocity & $P G V=\max |v(t)|$ & [25] \\
\hline PGV/PGA & $\begin{array}{l}\text { Ratio between PGV and } \\
\text { PGA }\end{array}$ & PGV/PGA & \\
\hline PGD & $\begin{array}{l}\text { Peak Ground } \\
\text { Displacement }\end{array}$ & $P G D=\max |u(t)|$ & {$[25]$} \\
\hline$S I_{H}$ & $\begin{array}{l}\text { Spectrum or Housner } \\
\text { intensity }\end{array}$ & $\int_{0.1}^{2.5} S V(T, \xi) d T$ & [43] \\
\hline$I_{a}$ & Arias Intensity & $I_{a}=\frac{\pi}{2 g} \int_{0}^{\infty} a(t)^{2} d t$ & [44] \\
\hline$I_{v}$ & Energy density & $I_{v}=\int_{0} v(t)^{2} d t$ & [44] \\
\hline$I_{F}$ & Fajfar Index & $I_{F}=P G V \cdot t_{D}^{0.25}$ & [39] \\
\hline$t_{D}$ & Strong motion duration & $\begin{array}{c}t_{D}=0.95 \int_{0}^{t_{E}} a(t)^{2} d t-0.05 \int_{0}^{t_{E}} a(t)^{2} d t \\
\operatorname{Or} t_{D}=t_{95}-t_{5}\end{array}$ & [40] \\
\hline RMSA & $\begin{array}{l}\text { Root Mean Square } \\
\text { Acceleration }\end{array}$ & $R M S A=\left(\frac{1}{t_{E}} \int_{0}^{t_{E}} a(t)^{2} d t\right)^{\frac{1}{2}}$ & [45] \\
\hline RMSV & $\begin{array}{l}\text { Root Mean Square } \\
\text { Velocity }\end{array}$ & $R M S V=\left(\frac{1}{t_{E}} \int_{0}^{t_{E}} v(t)^{2} d t\right)^{\frac{1}{2}}$ & [46] \\
\hline RMSD & $\begin{array}{l}\text { Root Mean Square } \\
\text { Displacement }\end{array}$ & $R M S D=\left(\frac{1}{t_{E}} \int_{0}^{t_{E}} u(t)^{2} d t\right)^{\frac{1}{2}}$ & {$[46]$} \\
\hline CAV & $\begin{array}{l}\text { Cumulative Absolute } \\
\text { Velocity }\end{array}$ & $C A V=\int_{0}^{t_{E}}|a(t)| d t$ & [42] \\
\hline$T_{m}$ & Mean period & $T_{m}=\frac{\sum_{i} C_{i}^{2}\left(\frac{1}{f_{i}}\right)}{\sum_{i} C_{i}^{2}}$ & [41] \\
\hline$L_{m}$ & Characteristic length scale & $L_{m}=T_{m}^{2} \cdot P G A$ & {$[38],[47]$} \\
\hline
\end{tabular}

\subsection{Selection of records}

The seismic records were mainly chosen from the database of the 2016-2017 Central Italy Earthquake. The 2016-2017 Earthquake severely hit Central Italy with a long and strong seismic swarm, started on August, 24 ${ }^{\text {th }}$ and ended in January 2017. Corrected records of the earthquakes considered for preliminary analyses are available in the Engineering Strong-Motion database (ESM [48]). The selection criterion is a magnitude ML greater than 4.0, so 50 earthquakes are available (East-West orientation). In order to obtain more meaningful results, extra 24 earthquakes were taken from the same database considering PGV values higher than $45 \mathrm{~cm} / \mathrm{s}$. Data and seismic parameters are shown in Table 6 (synthetic with site and event) and Table 6 (detailed with IMs).

Table 5 Selected earthquake records with dates and corresponding station IDs.

\begin{tabular}{r|lcccc}
\multicolumn{2}{r}{ Site } & Date & Time & M $_{\mathbf{L}}$ & \multicolumn{1}{c}{ Station ID } \\
\hline $1-5$ & Accumuli & $24 / 08 / 2016$ & $01: 36$ & 6.0 & FEMA, FOC, CLF, NRC, AMT \\
\hline $6-10$ & Norcia & $24 / 08 / 2016$ & $02: 33$ & 5.4 & FOC, NRC, FEMA, GUMA, AMT \\
\hline
\end{tabular}




\begin{tabular}{c|lcccl}
\hline $11-16$ & C.S.Angelo & $26 / 10 / 2016$ & $17: 10$ & 5.4 & FOC, FEMA, MCV, MNF, CNE, CMI \\
\hline $17-22$ & Ussita & $26 / 10 / 2016$ & $19: 18$ & 5.9 & MCV, FOC, CLF, MNF, CMI, CNE \\
\hline & & & & $\begin{array}{l}\text { T1219, MCV, MNF, FOC, T1213, CLO, } \\
\text { T1214, ACC, CNE, AMT, NRC, T1201, } \\
\text { NOR }\end{array}$ \\
\hline $36-40$ & Norcia & $30 / 10 / 2016$ & $06: 40$ & 6.1 & Amatrice_1 \\
\hline $41-45$ & Amatrice_2 & $18 / 01 / 2017$ & $10: 14$ & 5.4 & ASP, CNE, NRC, RQT, PCB \\
\hline $46-50$ & Amatrice_3 & $18 / 01 / 2017$ & $10: 25$ & 5.3 & RQT, ACT, AMT, CNE, MSCT \\
\hline
\end{tabular}

\begin{tabular}{|c|c|c|c|c|c|}
\hline & High PGV events & Date & Time & $\mathbf{M}_{\mathbf{w}}$ & Station ID \\
\hline 51 & Southern_Iran & $26 / 12 / 2003$ & $01: 56$ & 6.6 & BAM1 \\
\hline 52 & $\begin{array}{l}\text { Northern_and_central_Ira } \\
\mathrm{n}\end{array}$ & $16 / 09 / 1978$ & $15: 35$ & 7.3 & $\mathrm{TAB}$ \\
\hline 53 & Turkey & $13 / 03 / 1992$ & $17: 18$ & 6.6 & 2402 \\
\hline $54-55$ & Duzce & $12 / 11 / 1999$ & $16: 57$ & 7.3 & 8101,1401 \\
\hline 56 & Romania & $04 / 03 / 1977$ & 19:21 & 7.5 & A39 \\
\hline 57 & Irpinia & $23 / 11 / 1980$ & 18:34 & 6.9 & STR \\
\hline 58 & Friuli_2nd_shock & $15 / 09 / 1976$ & $03: 15$ & 5.9 & GMN \\
\hline 59 & Northern_Uzbekistan & $17 / 05 / 1976$ & 02:58 & 6.7 & GZL \\
\hline 60 & Turkey & $13 / 09 / 1999$ & $11: 55$ & 5.8 & 4107 \\
\hline $61-65$ & Emilia_2nd_shock & $29 / 05 / 2012$ & 07:00 & 6.0 & MIRE, MRN, MIRH, MIR01, MIR02 \\
\hline 66 & $\begin{array}{l}\text { Northern_Balkan_peninsu } \\
\text { la }\end{array}$ & $15 / 04 / 1979$ & 06:19 & 6.9 & BAR \\
\hline 67 & Greece & $15 / 06 / 1995$ & 00:15 & 6.5 & AIGA \\
\hline 68 & Western_Iran & $20 / 06 / 1990$ & $21: 00$ & 7.4 & A6211 \\
\hline 69 & $\begin{array}{l}\text { Northwestern_Balkan_pe } \\
\text { ninsula }\end{array}$ & $15 / 04 / 1979$ & 06:19 & 6.9 & ULO \\
\hline 70 & Emilia_1st_shock & $20 / 05 / 2012$ & 02:03 & 6.1 & $\mathrm{MRN}$ \\
\hline 71 & Turkey & $01 / 10 / 1995$ & $15: 57$ & 6.0 & 302 \\
\hline 72 & L'Aquila & $06 / 04 / 2009$ & $01: 32$ & 6.1 & $\mathrm{AQV}$ \\
\hline 73 & Northern_Italy & $29 / 05 / 2012$ & $10: 55$ & 5.5 & $\mathrm{~T} 0819$ \\
\hline 74 & Southern_Iran & $20 / 06 / 1994$ & 09:09 & 5.8 & A3297 \\
\hline
\end{tabular}

Table 6 Selected earthquake records with the corresponding IMs.

\begin{tabular}{|c|c|c|c|c|c|c|c|c|c|c|c|c|c|c|c|}
\hline RECORD & $\begin{array}{l}\text { PGA } \\
{[\mathrm{g}]} \\
\end{array}$ & $\begin{array}{l}\text { PGV } \\
{[\mathrm{cm} / \mathrm{s}]}\end{array}$ & $\begin{array}{l}\text { PGV_PGA } \\
{[\mathrm{cm} / \mathrm{s} / \mathbf{g}]}\end{array}$ & $\begin{array}{l}\text { PGD } \\
{[\mathrm{cm}]}\end{array}$ & SIH & Ia & Iv & $\begin{array}{l}\text { tD } \\
{[s]}\end{array}$ & IF & $\begin{array}{l}\text { RMSA } \\
{\left[\mathrm{cm}^{2} / \mathbf{s}^{4}\right]}\end{array}$ & $\begin{array}{l}\text { RMSV } \\
{\left[\mathrm{cm}^{2} / \mathbf{s}^{2}\right]}\end{array}$ & $\begin{array}{l}\text { RMSD } \\
{\left[\mathrm{cm}^{2}\right]}\end{array}$ & $\begin{array}{l}\text { CA } \\
\text { V } \\
\end{array}$ & $\begin{array}{l}\mathbf{T} \\
\mathbf{m}\end{array}$ & Lm \\
\hline \multirow{3}{*}{ 19760517_GZL } & & & & & 2023 & 4.8 & 3969. & 24. & 140. & & & & 10. & 0.4 & 0.1 \\
\hline & 0.72 & 63.28 & 87.61 & 20.97 & 28 & 1 & 54 & 35 & 58 & 1.50 & 16.75 & 7.30 & 95 & 2 & 30 \\
\hline & & & & & 2264 & 2.4 & 2706. & 12. & 127. & & & & 5.2 & 0.7 & 0.3 \\
\hline \multirow[t]{2}{*}{ 19760915_GMN } & 0.64 & 68.44 & 106.26 & 11.54 & 22 & 0 & 90 & 13 & 71 & 1.16 & 15.59 & 3.14 & 9 & 4 & 57 \\
\hline & & & & & 1301 & 0.4 & 1346. & 2.0 & 37.1 & & & & 3.5 & 1.2 & 0.2 \\
\hline \multirow[t]{2}{*}{ 19770304_A39 } & 0.17 & 31.13 & 183.49 & 9.63 & 65 & 0 & 71 & 3 & 8 & 0.33 & 7.39 & 2.84 & 3 & 1 & 47 \\
\hline & & & & & 3050 & 10. & 11468 & 54. & 233. & & & & 23. & 0.4 & 0.2 \\
\hline \multirow[t]{2}{*}{ 19780916_ТАВ } & 0.84 & 85.99 & 102.44 & 33.41 & 90 & 72 & .04 & 21 & 34 & 1.61 & 20.11 & 12.16 & 69 & 9 & 02 \\
\hline & & & & & 2458 & 3.0 & 3764. & 15. & 99.6 & & & & 13. & 0.7 & 0.2 \\
\hline \multirow[t]{2}{*}{ 19790415_BAR } & 0.36 & 50.42 & 140.06 & 13.79 & 75 & 1 & 47 & 24 & 2 & 0.80 & 11.42 & 2.81 & 05 & 6 & 08 \\
\hline & & & & & 1780 & 1.2 & 2190. & 6.3 & 75.8 & & & & 9.3 & 0.8 & 0.1 \\
\hline \multirow[t]{2}{*}{ 19790415_ULO } & 0.24 & 47.67 & 201.36 & 13.30 & 45 & 6 & 60 & 9 & 0 & 0.50 & 8.08 & 2.26 & 4 & 4 & 68 \\
\hline & & & & & 1665 & 1.4 & 4802. & 7.5 & 116. & & & & 9.9 & 0.8 & 0.2 \\
\hline 19801123 STR & 0.32 & 70.32 & 222.73 & 26.87 & 35 & 8 & 38 & 0 & 38 & 0.45 & 10.50 & 5.58 & 9 & 5 & 29 \\
\hline 19900620_A621 & & & & & 1286 & 4.6 & 1744. & 23. & 81.7 & & & & 17. & 0.3 & 0.0 \\
\hline \multirow[t]{2}{*}{1} & 0.58 & 37.12 & 63.55 & 9.94 & 40 & 6 & 18 & 55 & 8 & 0.87 & 6.68 & 2.36 & 27 & 1 & 55 \\
\hline & & & & & 2057 & 1.7 & 4290. & 8.9 & 132. & & & & 6.3 & 0.8 & 0.3 \\
\hline 19920313_2402 & 0.49 & 76.68 & 157.30 & 28.27 & 11 & 6 & 08 & 0 & 44 & 0.89 & 17.34 & 8.64 & 3 & 3 & 39 \\
\hline \multirow{2}{*}{$\begin{array}{l}\text { 19940620_A329 } \\
7\end{array}$} & & & & & 5735 & 5.9 & 365.3 & 30. & 75.1 & & & & 9.9 & 0.1 & 0.0 \\
\hline & 1.01 & 32.06 & 31.60 & 4.17 & 7 & 7 & 2 & 23 & 8 & 1.30 & 3.91 & 0.82 & 9 & 6 & 26 \\
\hline \multirow[b]{2}{*}{ 19950615_AIGA } & & & & & 1155 & 0.9 & 664.5 & 5.0 & 59.3 & & & & 2.8 & 0.5 & 0.1 \\
\hline & 0.50 & 39.67 & 79.62 & 8.32 & 68 & 9 & 0 & 2 & 8 & 0.60 & 5.83 & 1.40 & 4 & 1 & 31 \\
\hline
\end{tabular}




\begin{tabular}{|c|c|c|c|c|c|c|c|c|c|c|c|c|c|c|c|}
\hline & & & & & 2042 & 2.0 & 3890. & 10. & 77.8 & & & & 10. & 0.8 & 0.2 \\
\hline 199510010302 & 0.33 & 43.53 & 133.20 & 9.29 & 19 & 2 & 31 & 22 & 3 & 0.78 & 13.73 & 4.06 & 72 & 9 & 57 \\
\hline & & & & & 2371 & 1.8 & 3346. & 9.2 & 109. & & & & 6.5 & 0.9 & 0.5 \\
\hline $19990913 \quad 4107$ & 0.62 & 62.74 & 100.60 & 20.06 & 21 & 3 & 37 & 8 & 50 & 0.54 & 8.69 & 2.38 & 2 & 4 & 55 \\
\hline & & & & & 2363 & 2.5 & 3408. & 12. & 124. & & & & 6.8 & 0.7 & 0.5 \\
\hline \multirow[t]{2}{*}{ 19991112_1401 } & 0.82 & 65.90 & 79.97 & 11.18 & 06 & 1 & 72 & 70 & 40 & 0.77 & 10.91 & 2.91 & 9 & 9 & 10 \\
\hline & & & & & 2640 & 3.0 & 14197 & 15 . & 164. & & & & 10. & 0.8 & 0.3 \\
\hline 199911128101 & 0.53 & 82.66 & 157.42 & 55.61 & 81 & 7 & .93 & 52 & 07 & 1.11 & 30.45 & 22.29 & 44 & 2 & 55 \\
\hline 20031226_BAM & & & & & 3825 & 8.7 & 7771. & 44. & 310. & & & & 15. & 0.4 & 0.1 \\
\hline 1 & 0.86 & 120.59 & 140.22 & 31.97 & 62 & 2 & 42 & 05 & 68 & 1.39 & 15.65 & 4.56 & 36 & 7 & 91 \\
\hline & & & & & 1286 & 2.8 & 867.6 & 14. & 78.1 & & & & 8.4 & 0.3 & 0.0 \\
\hline 20090406 AQV & 0.66 & 40.21 & 61.22 & 6.79 & 09 & 2 & 8 & 28 & 6 & 0.63 & 4.40 & 0.74 & 3 & 3 & 73 \\
\hline & & & & & 9899 & 0.7 & 472.9 & 3.6 & 41.3 & & & & 3.6 & 0.4 & 0.0 \\
\hline $20120520 \mathrm{MRN}$ & 0.26 & 29.97 & 114.29 & 8.27 & 9 & 1 & 7 & 2 & 3 & 0.32 & 3.34 & 1.08 & 9 & 6 & 56 \\
\hline 20120529 MIR0 & & & & & 1319 & 1.5 & 973.0 & 7.9 & 52.6 & & & & 5.7 & 0.4 & 0.0 \\
\hline 1 & 0.42 & 31.33 & 74.70 & 8.25 & 86 & 8 & 2 & 9 & 6 & 0.55 & 5.62 & 1.59 & 7 & 6 & 87 \\
\hline 20120529 MIR0 & & & & & 9524 & 0.7 & 895.6 & 3.5 & 49.8 & & & & 4.4 & 0.5 & 0.0 \\
\hline 2 & 0.22 & 36.40 & 167.64 & 11.99 & 7 & 0 & 2 & 2 & 6 & 0.39 & 5.72 & 2.70 & 0 & 2 & 58 \\
\hline & & & & & 9017 & 0.6 & 569.6 & 3.0 & 36.3 & & & & 4.0 & 0.4 & 0.0 \\
\hline 20120529_MIRE & 0.18 & 27.49 & 155.66 & 8.27 & 3 & 0 & 2 & 4 & 1 & 0.37 & 4.48 & 1.82 & 8 & 9 & 43 \\
\hline 20120529 MIR & & & & & 7094 & 0.2 & 432.6 & 1.3 & 26.4 & & & & 2.5 & 0.6 & 0.0 \\
\hline $\mathrm{H}$ & 0.15 & 24.74 & 165.30 & 8.26 & 5 & 6 & 3 & 0 & 0 & 0.24 & 3.83 & 1.80 & 7 & 5 & 62 \\
\hline & & & & & 9078 & 0.7 & 594.4 & 4.0 & 40.3 & & & & 4.8 & 0.4 & 0.0 \\
\hline $20120529 \mathrm{MRN}$ & 0.22 & 28.49 & 127.87 & 9.35 & 5 & 9 & 2 & 0 & 0 & 0.40 & 4.52 & 1.91 & 2 & 0 & 36 \\
\hline 20120529_T081 & & & & & 9770 & 0.4 & 445.5 & 2.5 & 53.1 & & & & 2.3 & 0.5 & 0.0 \\
\hline 9 & 0.26 & 42.27 & 163.13 & 8.83 & 4 & 9 & 4 & 0 & 4 & 0.36 & 4.37 & 1.52 & 6 & 4 & 74 \\
\hline 201608242 _A & & & & & 1350 & 0.0 & & 0.2 & & & & & 0.9 & 0.2 & 0.0 \\
\hline MT & 0.11 & 3.97 & 36.89 & 0.66 & 9 & 6 & 13.36 & 9 & 2.91 & 0.14 & 0.81 & 0.16 & 0 & 9 & 09 \\
\hline 20160824_2_FE & & & & & & 0.0 & & 0.1 & & & & & 0.8 & 0.1 & 0.0 \\
\hline MA & 0.06 & 1.96 & 35.42 & 0.17 & 4007 & 3 & 2.45 & 3 & 1.18 & 0.05 & 0.19 & 0.03 & 5 & 9 & 02 \\
\hline 20160824_2_FO & & & & & & 0.1 & & 0.9 & & & & & 1.7 & 0.1 & 0.0 \\
\hline $\mathrm{C}$ & 0.18 & 2.65 & 14.88 & 0.11 & 2959 & 9 & 4.48 & 6 & 2.62 & 0.25 & 0.48 & 0.02 & 9 & 2 & 02 \\
\hline $201608242 \mathrm{GU}$ & & & & & & 0.0 & & 0.1 & & & & & 1.2 & 0.3 & 0.0 \\
\hline MA & 0.05 & 2.91 & 60.27 & 0.30 & 7712 & 4 & 9.51 & 9 & 1.92 & 0.06 & 0.38 & 0.04 & 9 & 5 & 06 \\
\hline 201608242 NR & & & & & 3922 & 0.1 & & 0.9 & & & & & 1.9 & 0.3 & 0.0 \\
\hline $\mathrm{C}$ & 0.17 & 9.80 & 57.58 & 1.72 & 0 & 9 & 86.31 & 8 & 9.74 & 0.26 & 2.13 & 0.39 & 8 & 7 & 23 \\
\hline & & & & & 7329 & 1.8 & 337.9 & 9.5 & 76.5 & & & & 3.8 & 0.2 & 0.0 \\
\hline 20160824_AMT & 0.87 & 43.55 & 50.21 & 3.27 & 1 & 9 & 3 & 3 & 2 & 0.92 & 4.68 & 0.47 & 1 & 9 & 73 \\
\hline & & & & & 3440 & 0.1 & 107.8 & 0.9 & & & & & 2.2 & 0.5 & 0.0 \\
\hline 20160824_CLF & 0.13 & 8.70 & 69.42 & 1.56 & 1 & 8 & 9 & 2 & 8.51 & 0.21 & 1.94 & 0.39 & 1 & 2 & 34 \\
\hline 20160824 FEM & & & & & 4219 & 0.3 & 128.5 & 1.5 & 16.2 & & & & 2.0 & 0.4 & 0.0 \\
\hline A & 0.25 & 14.56 & 58.93 & 2.59 & 9 & 0 & 7 & 4 & 2 & 0.21 & 1.72 & 0.43 & 7 & 2 & 44 \\
\hline & & & & & 1706 & 0.3 & & 1.8 & & & & & 2.3 & 0.1 & 0.0 \\
\hline 20160824 FOC & 0.26 & 8.10 & 31.01 & 0.83 & 0 & 6 & 30.03 & 3 & 9.42 & 0.33 & 1.11 & 0.24 & 3 & 8 & 08 \\
\hline & & & & & 1043 & 1.0 & 621.7 & 5.2 & 45.1 & & & & 4.1 & 0.4 & 0.0 \\
\hline 20160824_NRC & 0.36 & 29.75 & 82.71 & 5.32 & 68 & 4 & 2 & 8 & 0 & 0.61 & 5.76 & 1.44 & 6 & 4 & 71 \\
\hline 20161026_2_C & & & & & 1271 & 2.4 & 924.4 & 12. & 104. & & & & 4.3 & 0.4 & 0.1 \\
\hline MI & 0.72 & 55.70 & 77.30 & 5.57 & 43 & 3 & 7 & 30 & 31 & 1.12 & 8.78 & 0.90 & 6 & 4 & 39 \\
\hline 20161026_2_CN & & & & & 3305 & 1.1 & 138.5 & 5.9 & 27.1 & & & & 3.6 & 0.2 & 0.0 \\
\hline $\mathrm{E}$ & 0.56 & 17.34 & 31.18 & 1.23 & 2 & 8 & 0 & 7 & 0 & 0.75 & 3.23 & 0.25 & 2 & 6 & 36 \\
\hline 20161026_2_FE & & & & & 2273 & 0.2 & & 1.1 & & & & & 1.7 & 0.2 & 0.0 \\
\hline MA & 0.20 & 8.77 & 44.34 & 0.84 & 4 & 3 & 44.13 & 9 & 9.15 & 0.22 & 1.21 & 0.13 & 6 & 9 & 16 \\
\hline 201610262 FO & & & & & 1543 & 0.5 & & 2.5 & 16.4 & & & & 2.2 & 0.2 & 0.0 \\
\hline $\mathrm{C}$ & 0.34 & 13.04 & 38.63 & 0.47 & 3 & 0 & 37.01 & 3 & 5 & 0.44 & 1.50 & 0.09 & 9 & 0 & 13 \\
\hline 20161026_2_M & & & & & & 0.2 & & 1.0 & & & & & 1.6 & 0.1 & 0.0 \\
\hline & 0.21 & 4.78 & 23.31 & 0.31 & 7874 & 1 & 10.00 & 8 & 4.87 & 0.30 & 0.81 & 0.07 & 2 & 5 & 05 \\
\hline 201610262 2_M & & & & & & 0.0 & & 0.0 & & & & & 0.4 & 0.2 & 0.0 \\
\hline $\mathrm{NF}$ & 0.06 & 1.66 & 27.12 & 0.19 & 4836 & 1 & 1.92 & 7 & 0.85 & 0.07 & 0.31 & 0.04 & 6 & 5 & 04 \\
\hline & & & & & 4180 & 0.2 & 192.5 & 1.0 & 12.1 & & & & 3.0 & 0.6 & 0.0 \\
\hline 20161026_CLF & 0.12 & 11.90 & 95.44 & 2.48 & 7 & 2 & 0 & 9 & 7 & 0.23 & 2.69 & 0.51 & 2 & 8 & 58 \\
\hline & & & & & 1386 & 2.2 & 926.5 & 11. & 80.6 & & & & 5.7 & 0.4 & 0.1 \\
\hline 20161026_CMI & 0.65 & 43.76 & 67.26 & 6.64 & 87 & 7 & 5 & 51 & 2 & 0.93 & 7.34 & 1.13 & 5 & 3 & 20 \\
\hline & & & & & 7794 & 1.1 & 343.8 & 5.9 & 35.9 & & & & 3.8 & 0.3 & 0.0 \\
\hline 20161026_CNE & 0.54 & 23.08 & 42.96 & 2.73 & 7 & 7 & 0 & 0 & 6 & 0.74 & 4.94 & 0.79 & 8 & 5 & 67 \\
\hline & & & & & 3063 & 2.0 & 160.6 & 10. & 35.7 & & & & 5.5 & 0.2 & 0.0 \\
\hline 20161026 FOC & 0.62 & 19.99 & 32.05 & 1.33 & 5 & 3 & 0 & 27 & 9 & 0.56 & 2.00 & 0.22 & 4 & 1 & 27 \\
\hline & & & & & 2716 & 0.8 & & 4.3 & 18.3 & & & & 3.6 & 0.1 & 0.0 \\
\hline 20161026_MCV & 0.38 & 12.70 & 33.02 & 1.47 & 8 & 6 & 60.08 & 4 & 2 & 0.57 & 1.89 & 0.36 & 2 & 6 & 10 \\
\hline & & & & & 2342 & 0.0 & & 0.4 & & & & & 1.3 & 0.2 & 0.0 \\
\hline 20161026_MNF & 0.12 & 8.26 & 68.37 & 3.01 & 1 & 9 & 35.73 & 3 & 6.71 & 0.13 & 1.11 & 0.81 & 0 & 8 & 10 \\
\hline & & & & & 1365 & 2.0 & 1146. & 10. & 78.7 & & & & 6.2 & 0.4 & 0.0 \\
\hline 20161030 ACC & 0.43 & 44.08 & 101.53 & 14.30 & 77 & 1 & 55 & 18 & 3 & 0.66 & 6.34 & 2.33 & 7 & 0 & 69 \\
\hline & & & & & 8869 & 1.5 & 667.0 & 7.9 & 63.5 & & & & 4.8 & 0.3 & 0.0 \\
\hline 20161030 AMT & 0.53 & 37.91 & 71.31 & 6.02 & 3 & 6 & 5 & 1 & 9 & 0.71 & 5.23 & 1.72 & 6 & 8 & 77 \\
\hline & & & & & 2293 & 2.4 & 2849. & 12. & 98.0 & & & & 8.9 & 0.6 & 0.1 \\
\hline 20161030_CLO & 0.43 & 52.23 & 122.40 & 14.13 & 35 & 6 & 94 & 42 & 6 & 0.71 & 8.27 & 2.59 & 7 & 6 & 84 \\
\hline & & & & & 1253 & 1.7 & 1153. & 8.9 & 66.1 & & & & 5.3 & 0.5 & 0.1 \\
\hline 20161030_CNE & 0.48 & 38.24 & 80.37 & 11.24 & 39 & 7 & 56 & 6 & 5 & 0.64 & 6.61 & 2.83 & 3 & 4 & 36 \\
\hline & & & & & 2734 & 2.2 & 177.0 & 11. & 23.1 & & & & 9.0 & 0.1 & 0.0 \\
\hline 20161030_FOC & 0.38 & 12.55 & 33.08 & 3.79 & 3 & 7 & 6 & 50 & 2 & 0.75 & 2.62 & 1.05 & 2 & 8 & 12 \\
\hline
\end{tabular}




\begin{tabular}{|c|c|c|c|c|c|c|c|c|c|c|c|c|c|c|c|}
\hline & & & & & 2381 & 0.9 & & 4.8 & 12.4 & & & & 6.0 & 0.1 & 0.0 \\
\hline 20161030 MCV & 0.29 & 8.35 & 28.63 & 2.75 & 4 & 6 & 73.13 & 7 & 1 & 0.42 & 1.45 & 0.73 & 3 & 6 & 07 \\
\hline \multirow{3}{*}{ 20161030_MNF } & & & & & 1886 & 0.1 & & 0.8 & & & & & 2.3 & 0.2 & 0.0 \\
\hline & 0.13 & 6.42 & 48.21 & 3.30 & 8 & 6 & 51.08 & 2 & 6.10 & 0.17 & 1.15 & 0.89 & 6 & 7 & 10 \\
\hline & & & & & 2478 & 2.8 & 5522. & 14. & 109. & & & & 11. & 0.9 & 0.2 \\
\hline \multirow[t]{2}{*}{ 20161030_NOR } & 0.31 & 56.24 & 180.45 & 23.02 & 49 & 9 & 98 & 60 & 94 & 0.68 & 11.81 & 5.15 & 71 & 4 & 76 \\
\hline & & & & & 1987 & 3.6 & 3240. & 18. & 99.9 & & & & 11. & 0.5 & 0.1 \\
\hline 20161030_NRC & 0.49 & 48.29 & 99.44 & 17.98 & 58 & 3 & 99 & 36 & 7 & 1.02 & 11.94 & 4.40 & 16 & 8 & 63 \\
\hline 20161030_T120 & & & & & 7379 & 0.9 & 720.2 & 4.6 & 29.9 & & & & 4.5 & 0.4 & 0.0 \\
\hline 1 & 0.35 & 20.42 & 59.04 & 9.71 & 7 & 2 & 6 & 3 & 5 & 0.43 & 4.65 & 2.32 & 3 & 3 & 65 \\
\hline 20161030_T121 & & & & & 1485 & 5.5 & 1432. & 28. & 139. & & & & 10. & 0.2 & 0.0 \\
\hline 3 & 0.79 & 60.73 & 76.45 & 12.42 & 96 & 6 & 70 & 11 & 84 & 1.09 & 7.12 & 3.47 & 97 & 6 & 54 \\
\hline 20161030_T121 & & & & & 1283 & 3.8 & 1566. & 19. & 113. & & & & 9.3 & 0.2 & 0.0 \\
\hline 4 & 0.60 & 53.95 & 89.21 & 21.28 & 57 & 4 & 69 & 41 & 23 & 0.85 & 5.89 & 3.91 & 7 & 8 & 49 \\
\hline 20161030_T121 & & & & & 1800 & 0.4 & & 2.4 & & & & & 4.1 & 0.2 & 0.0 \\
\hline 9 & 0.16 & 6.97 & 44.77 & 2.11 & 1 & 9 & 62.14 & 6 & 8.72 & 0.23 & 1.01 & 0.46 & 7 & 2 & 07 \\
\hline 20170118_2_AC & & & & & & 0.0 & & 0.0 & & & & & 0.4 & 0.1 & 0.0 \\
\hline $\mathrm{T}$ & 0.08 & 1.73 & 22.75 & 0.11 & 2698 & 2 & 0.70 & 9 & 0.94 & 0.08 & 0.20 & 0.02 & 8 & 4 & 01 \\
\hline 20170118_2_CN & & & & & & 0.0 & & 0.0 & & & & & 0.6 & 0.2 & 0.0 \\
\hline $\mathrm{E}$ & 0.06 & 1.52 & 24.41 & 0.09 & 2802 & 2 & 1.32 & 9 & 0.84 & 0.07 & 0.23 & 0.01 & 3 & 0 & 02 \\
\hline 20170118_2_CS & & & & & & 0.0 & & 0.0 & & & & & 0.2 & 0.2 & 0.0 \\
\hline $\mathrm{C} \quad--$ & 0.04 & 1.26 & 30.29 & 0.14 & 2953 & 1 & 0.84 & 3 & 0.51 & 0.04 & 0.20 & 0.02 & 9 & 4 & 02 \\
\hline 20170118_2_PC & & & & & & 0.2 & & 1.3 & & & & & 1.2 & 0.1 & 0.0 \\
\hline $\mathrm{B}$ & 0.27 & 5.03 & 18.93 & 0.53 & 9013 & 7 & 8.03 & 7 & 5.44 & 0.29 & 0.60 & 0.06 & 6 & 1 & 03 \\
\hline 20170118_2_RQ & & & & & & 0.0 & & 0.1 & & & & & 0.6 & 0.1 & 0.0 \\
\hline $\mathrm{T}$ & 0.09 & 1.58 & 18.54 & 0.13 & 3284 & 2 & 1.14 & 2 & 0.94 & 0.09 & 0.24 & 0.03 & 1 & 3 & 01 \\
\hline 20170118_3_AC & & & & & & 0.0 & & 0.1 & & & & & 0.7 & 0.1 & 0.0 \\
\hline $\mathrm{T} \quad--$ & 0.10 & 3.22 & 32.03 & 0.20 & 4102 & 4 & 1.47 & 9 & 2.12 & 0.11 & 0.28 & 0.05 & 8 & 3 & 02 \\
\hline 20170118_3_A & & & & & 1943 & 0.1 & & 0.7 & & & & & 1.2 & 0.2 & 0.0 \\
\hline MT & 0.16 & 10.18 & 63.99 & 0.89 & 8 & 5 & 26.79 & 6 & 9.51 & 0.21 & 1.08 & 0.16 & 6 & 9 & 13 \\
\hline 20170118_3_CN & & & & & & 0.0 & & 0.1 & & & & & 0.7 & 0.1 & 0.0 \\
\hline $\mathrm{E}$ & 0.05 & 1.47 & 30.86 & 0.09 & 2524 & 2 & 1.27 & 0 & 0.82 & 0.07 & 0.21 & 0.03 & 7 & 8 & 02 \\
\hline 20170118_3_MS & & & & & 4895 & 0.2 & 111.0 & 1.3 & 18.4 & & & & 1.9 & 0.4 & 0.0 \\
\hline & 0.23 & 17.03 & 75.52 & 2.38 & 3 & 7 & 1 & 9 & 8 & 0.35 & 2.86 & 0.64 & 5 & 6 & 47 \\
\hline 20170118_3_RQ & & & & & & 0.0 & & 0.1 & & & & & 0.9 & 0.1 & 0.0 \\
\hline $\mathrm{T}---2$ & 0.07 & 1.92 & 27.88 & 0.22 & 3808 & 4 & 1.57 & 9 & 1.28 & 0.11 & 0.27 & 0.06 & 6 & 2 & 01 \\
\hline & & & & & & 0.0 & & 0.1 & & & & & 0.7 & 0.1 & 0.0 \\
\hline 20170118_ASP & 0.11 & 2.97 & 27.75 & 0.57 & 7537 & 4 & 5.98 & 8 & 1.93 & 0.10 & 0.48 & 0.17 & 8 & 9 & 04 \\
\hline & & & & & & 0.0 & & 0.2 & & & & & 1.0 & 0.1 & 0.0 \\
\hline 20170118_CNE & 0.07 & 2.23 & 33.11 & 0.14 & 3944 & 4 & 2.65 & 0 & 1.48 & 0.10 & 0.31 & 0.04 & 0 & 8 & 02 \\
\hline & & & & & 1182 & 0.0 & & 0.0 & & & & & 1.0 & 0.5 & 0.0 \\
\hline 20170118_NRC & 0.04 & 2.38 & 61.01 & 0.60 & 4 & 2 & 15.36 & 9 & 1.30 & 0.06 & 0.65 & 0.16 & 1 & 5 & 12 \\
\hline & & & & & 4013 & 0.9 & 122.6 & 4.8 & 25.0 & & & & 3.0 & 0.2 & 0.0 \\
\hline 20170118_PCB & 0.41 & 16.91 & 41.44 & 1.32 & 6 & 5 & 0 & 0 & 4 & 0.71 & 3.21 & 0.28 & 0 & 4 & 24 \\
\hline & & & & & & 0.0 & & 0.4 & & & & & 1.0 & 0.1 & 0.0 \\
\hline 20170118_RQT & 0.11 & 3.28 & 29.54 & 0.53 & 7818 & 8 & 5.49 & 0 & 2.61 & 0.16 & 0.51 & 0.16 & 8 & 4 & 02 \\
\hline
\end{tabular}

\section{SENSITIVITY ANALYSIS AND CORRELATION CURVES}

To distinguish the most significant IMs, it is useful to calculate specific correlation coefficients. Indeed, a correlation analysis states the strength of association between the considered variables. The selection of an optimal IM is based upon the characteristics illustrated in [37]: efficiency, proficiency, practicality, sufficiency and hazard computability. While the latter two serve as secondary factors to support the selection of an optimal IM, the first ones are of primary importance. Efficiency is related to the amount of variation in the estimated demand for a given IM value [49]. The lower the dispersion coefficient $\beta_{D \mid I M}$, the more efficient the corresponding IM. Practicality is measured by the regression parameter $b$ (Equations (9)-(10)): if this parameter approaches zero, the corresponding IM is not significant for the demand estimation. Finally, the proficiency measures the composite effect of practicality and efficiency [37], and is given by $\zeta=\beta_{D \mid I M} / b$. A better IM corresponds to lower values of $\zeta$ and $\beta_{D \mid I M}$ and to higher values of $b$. Pearson's and Spearman's coefficients are used to have preliminary information on the relevance of each IM on the response. Indeed, the higher the correlation coefficient, the minor the dispersion and therefore the relevance of the IM. The Pearson's coefficient $c_{\text {Pearson }}$ expresses the linear dependency between the variables, according to the formula: 


$$
c_{\text {Pearson }}=\frac{\sum_{i=1}^{N}\left(X_{i}-\bar{X}\right)\left(Y_{i}-\bar{Y}\right)}{\sqrt{\sum_{i=1}^{N}\left(X_{i}-\bar{X}\right)^{2} \sum_{i=1}^{N}\left(Y_{i}-\bar{Y}\right)^{2}}} .
$$

where $N$ is the number of coupled variables, whereas the Spearman's coefficient $c_{\text {Spearman }}$ denotes the corresponding monotonic trends of the two variables to correlate:

$$
c_{\text {Spearman }}=1-\frac{6 \sum_{i=1}^{N} d_{i}}{N\left(N^{2}-1\right)}
$$

where $d_{i}$ is the difference between the ranks of two corresponding variables.

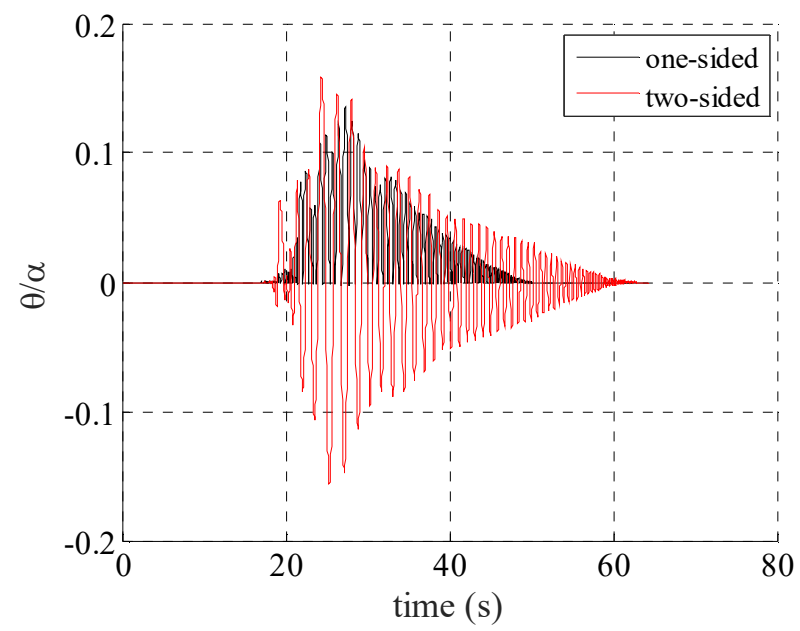

(a)

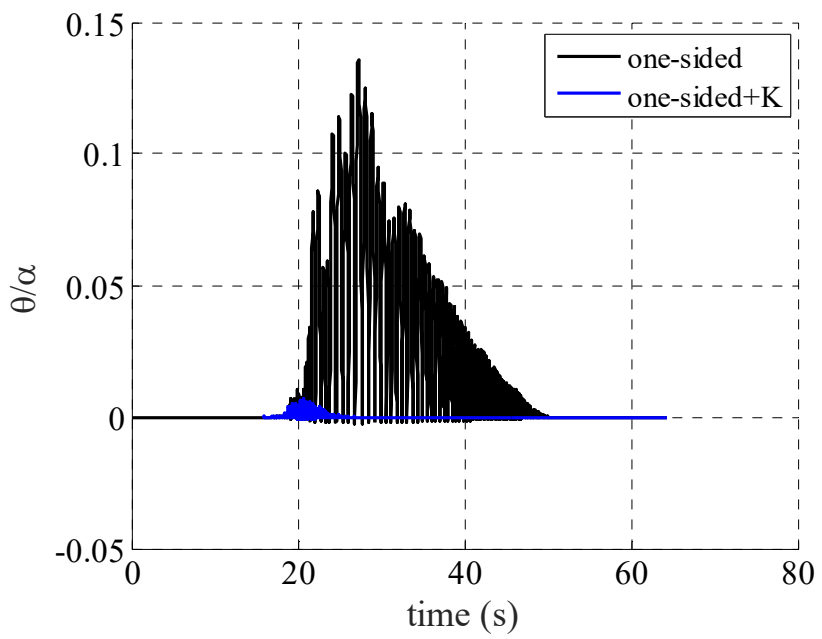

(b)

Figure 4. One realization of the stochastic analyses in one-sided, two-sided without restraints (a) and with restraints (b)-LSCH, earthquake 20120529_MIRH.

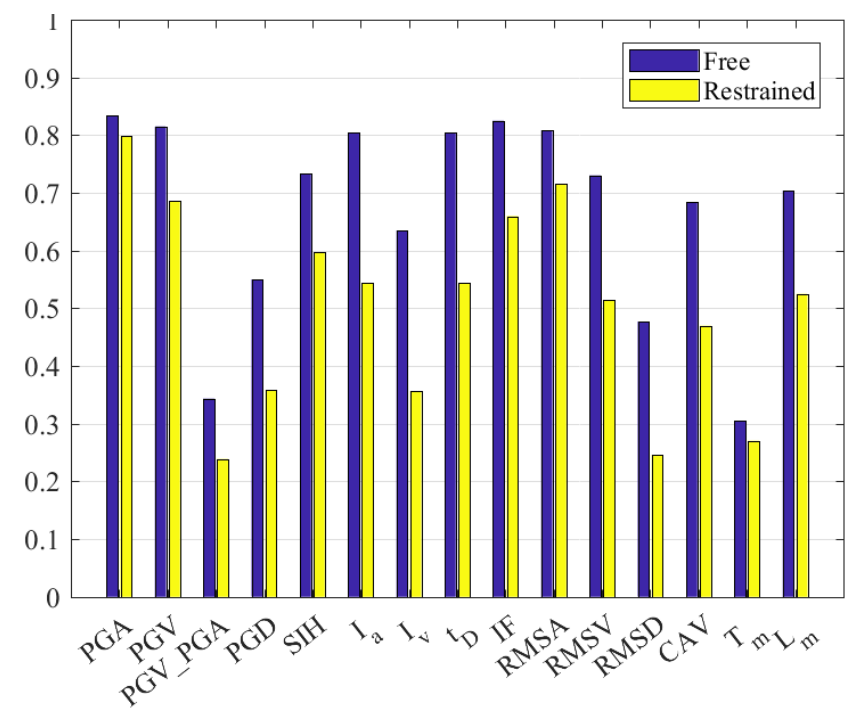

(a) 


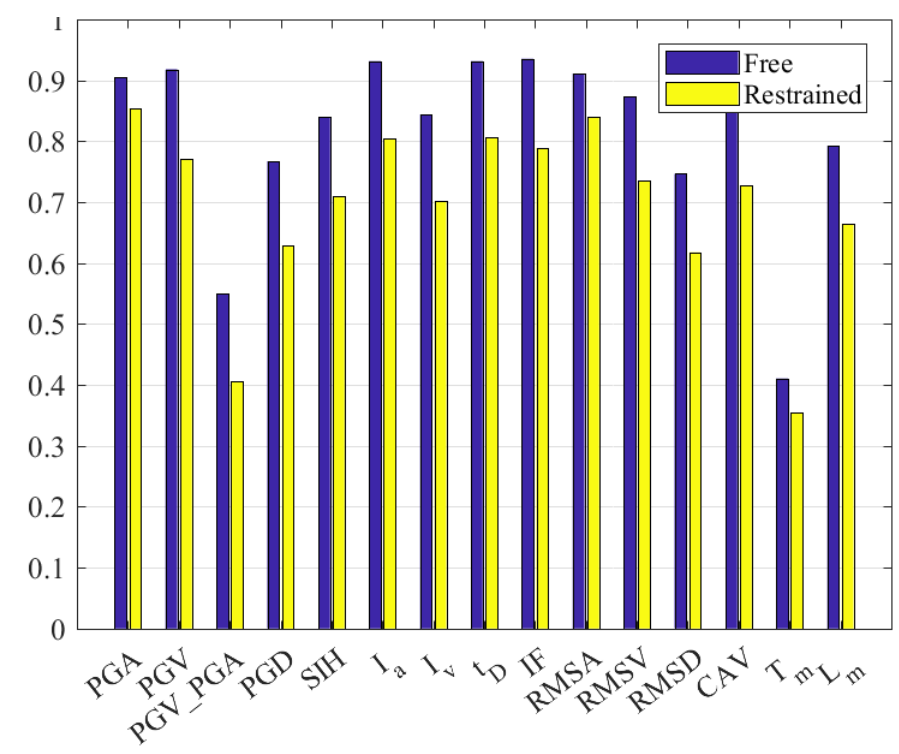

(b)

Figure 5. San Michele church (LSCH): Pearson's (a) and Spearman's (b) coefficients.

One realization of the stochastic analyses is reported in Figure 4. For the sake of comparison, the results in case of one-sided motion (taking into account the stiffness in compression of the sidewalls) and of two-sided motion (neglecting the sidewalls) are reported in Figure 4a. It is clear the rebound effect shown in the onesided motion due to the presence of the sidewalls. The behavior of the restrained configuration is displayed in Figure $4 \mathrm{~b}$. With the steel tie-rods the maximum normalized rotation is two orders of magnitude lower than that of the case without restraints.

For LSCH, with intermediate values of slenderness ratio $\alpha=0.07$ and radius vector $\mathrm{R}=4.4 \mathrm{~m}$, the linear correlation is generally good, with most of the Pearson's coefficients higher than 0.70 for the free case. In this configuration, the most representative IMs are: the Fajfar Index $I_{F}\left(c_{\text {Pearson }}=0.82\right)$, Peak Ground Acceleration PGA (0.83) and Peak Ground Velocity PGV (0.82). For the restrained case, the most relevant IMs are: PGA (0.80), Root Mean Square Acceleration RMSA (0.72) and PGV (0.69). The calculation has been performed for the free case in both one-sided (realistic case) and two-sided motion (absence of sidewalls or bed spring). It is interesting to notice that the correlation is sensitively better when the sidewalls are considered in the formulation (Figure 6).

In general, the restrained case is less linearly correlated than the free case, showing values always lower than those in the free case. Nevertheless, such reduction is generally negligible for the most relevant IMs. The Pearson's values have the higher differences between the case of free or restrained façade for Energy Density $\mathrm{I}_{\mathrm{v}}$ (percentage reduction from free to restrained by 44\%), Root Mean Square Displacement RMSD (48\%) and Peak Ground Displacement PGD (35\%). However, this reduction is not significant being the values of Pearson's coefficients in free condition equal to $0.63,0.48$ and 0.55 respectively, and therefore not so representative. The latter ones, together with mean period $\mathrm{T}_{\mathrm{m}}$ and ratio PGV/PGA, are for both cases the IMs associated to the worst correlation. 


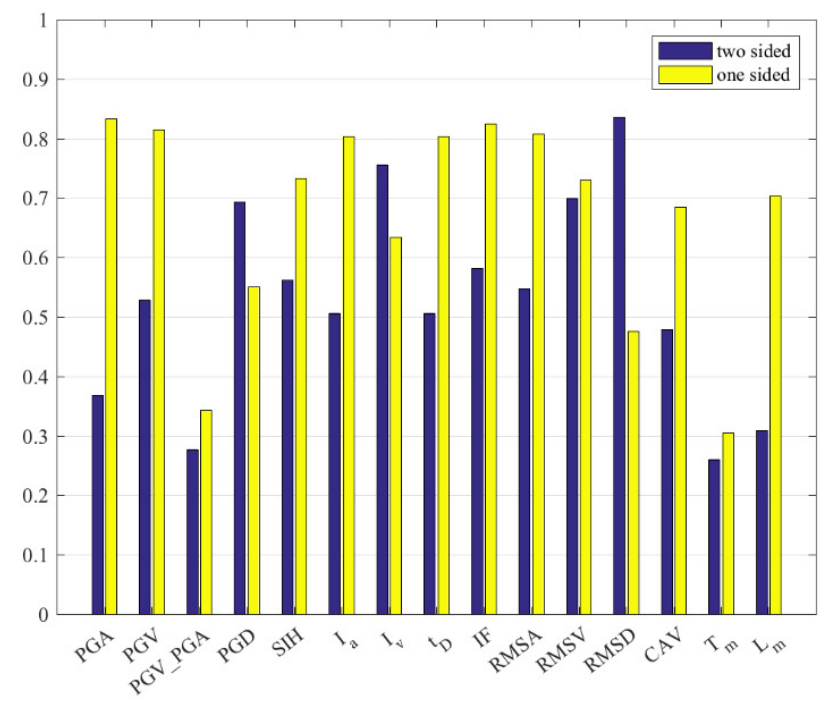

Figure 6. San Michele church (LSCH): comparison of Pearson's coefficients between one-sided (sidewalls included in the formulation) and two-sided (sidewalls neglected).

Figure 7 shows linear regressions associated to the coefficients with good (Figure 7b-d) and bad correlations (Figure 7a-c).

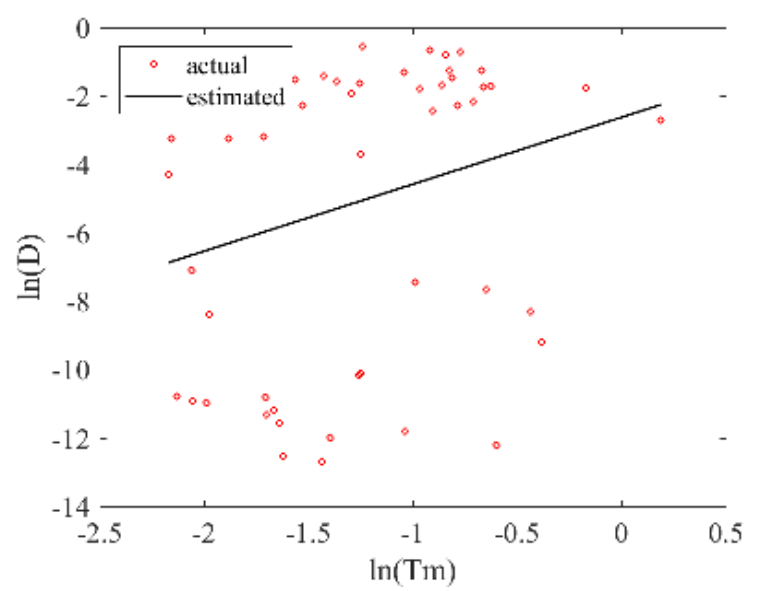

(a) SFILCH 1 sided - bad correlation

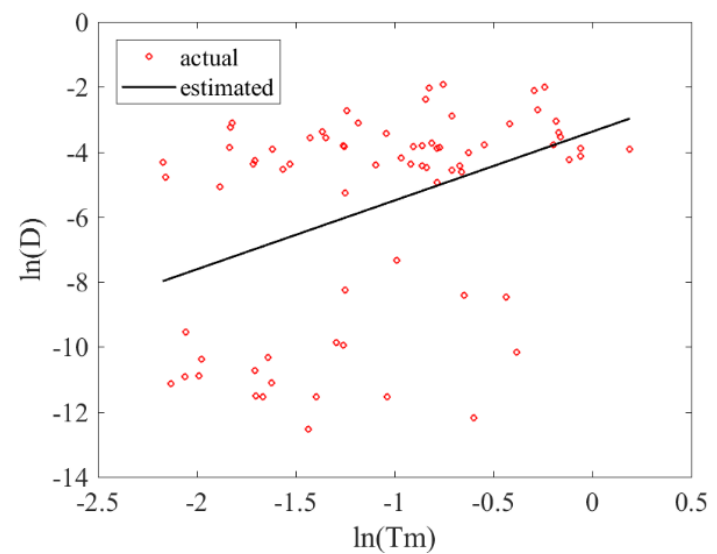

(c) SFILCH 1 sided $+\mathrm{K}$ - bad correlation

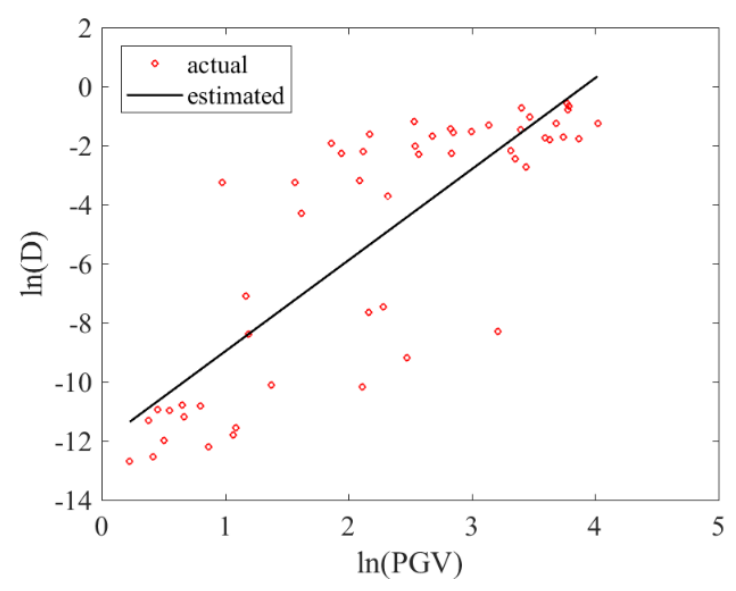

(b) SFILCH 1 sided - good correlation

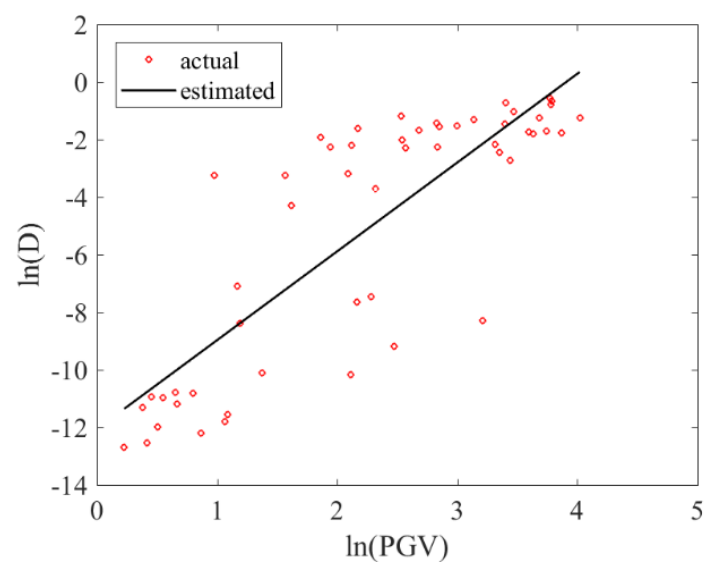

(d) SFILCH 1 sided $+\mathrm{K}-$ good correlation 
Figure 7 Linear regressions between demand and IMs (Equation (9)): SFILCH free - $\mathrm{T}_{\mathrm{m}}$ (a) and PGV (b); SFILCH restrained- $\mathrm{T}_{\mathrm{m}}(\mathrm{c})$ and $\mathrm{PGV}(\mathrm{d})$.

PGA and PGV are the best IMs to correlate the response after Spearman in both cases. For what concerns the Spearman's coefficients, they are similar independently from the considered case with percentage differences lower than $15 \%$. In particular, the greatest difference, equal to $26 \%$, is referred to PGV/PGA. The worst IM is the mean period $\mathrm{T}_{\mathrm{m}}$, greater in the free case $(0.41)$ than in the restrained one $(0.35)$.

The trend for SFILCH, the smaller and stockier rocking block, is opposite with respect to the previous one: now, the restrained case is better linearly correlated than the free case, showing values always greater than those in the free case (Figure 9). This makes reliable such an analysis for retrofitting purposes. The Pearson's values have the higher differences between the case of free or restrained façade for the PGV/PGA (percentage increase from free to restrained by $200 \%)$ and $\mathrm{T}_{\mathrm{m}}(190 \%)$. Although these percentages are much greater than $\mathrm{LSCH}$, they are not so meaningful being the values of Pearson's coefficients in restrained condition equal to 0.59 and 0.41 respectively. Also for this church, the most representative IMs are for one-sided motion of free configuration: the PGV $\left(c_{\text {Pearson }}=0.82\right)$, PGA $(0.79), I_{F}(0.79)$ and RMSA $(0.79)$. For the restrained case, the most relevant IMs are: PGA (0.91), RMSA (0.94) and PGV (0.84). PGV and $I_{F}$ are velocity based parameters, and it confirms the results available in the literature for which velocity is often more significant than acceleration or displacement [25]. Nevertheless, in this case acceleration plays a significant role as well as velocity. The worst IMs are the Energy Density $\mathrm{I}_{v}$, PGV/PGA, RMSD, PGD, $\mathrm{T}_{\mathrm{m}}$ (as in LSCH) and the characteristic length scale $\mathrm{L}_{\mathrm{m}}$. For instance, the minimum Pearson's coefficient is the mean period $\mathrm{T}_{\mathrm{m}}$, which is 0.14 (free) and 0.41 (restrained). Between Pearson's and Spearman's coefficients, the latter ones are much closer to one, expressing that the variables are well monotonically related.

Again, the Spearman's coefficients are similar one to each other, independently from the considered case with percentage differences lower than 5\% (with the exception of $\mathrm{T}_{\mathrm{m}}$, RMSD and PGV/PGA). In addition, high Spearman's values are associated to Arias Intensity $I_{a}$ and strong motion duration $t_{\mathrm{D}}$ (Figure 9 ). The worst IM is again $\mathrm{T}_{\mathrm{m}}$ (as in $\mathrm{LSCH}$ ), lower in free case $(0.28)$ than in the restrained one $(0.39)$.

Finally, the results for the façade of $\mathrm{SMVCH}$, the more slender and larger façade $(\alpha=0.06$ and $\mathrm{R}=10.7 \mathrm{~m})$, characterized by an inertia moment two orders of magnitude greater than that of LSCH (Table 2), imply higher dispersion. Indeed, the higher Pearson's coefficients are lower than 0.76 for the free case and lower than 0.64 for the restrained configuration. Anyway, the most efficient IMs for SFILCH are RMSV $\left(c_{\text {Pearson }}=0.76\right) \mathrm{I}_{\mathrm{a}}$ (0.69) and RMSD (0.73) for the free case. With the steel tie-rods, the most relevant IMs are. $\mathrm{I}_{\mathrm{F}}(0.64), \mathrm{PGV}$ (0.64) and the Housner Intensity SIH (0.60). For this façade, the differences of values of Pearson's coefficients in free and restrained configurations are negligible for PGV, SIH, $\mathrm{I}_{\mathrm{F}}, \mathrm{PGA}$.. The coefficient when considering PGV increases by $30 \%$ in case of restrained configuration. The worst IMs are PGA (free 0.44 , restrained 0.45 ), $\mathrm{Lm}$ (free 0.42, restrained 0.41), and Tm (free 0.15, restrained 0.35) and PGV/PGA (free 0.15, restrained 0.42), always showing a better linear correlation when tie-rods are taken into account. . $\mathrm{I}_{\mathrm{F}}(0.91)$ and PGV (0.90) in the free case the best IMs to reduce the dispersion of the results after Spearman. 


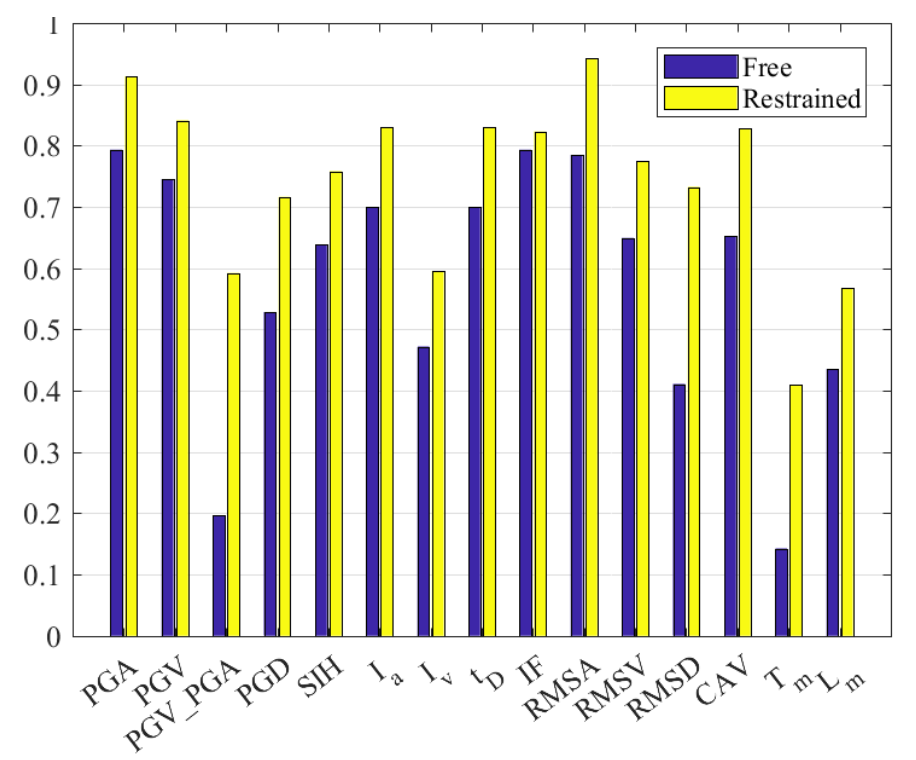

(a)

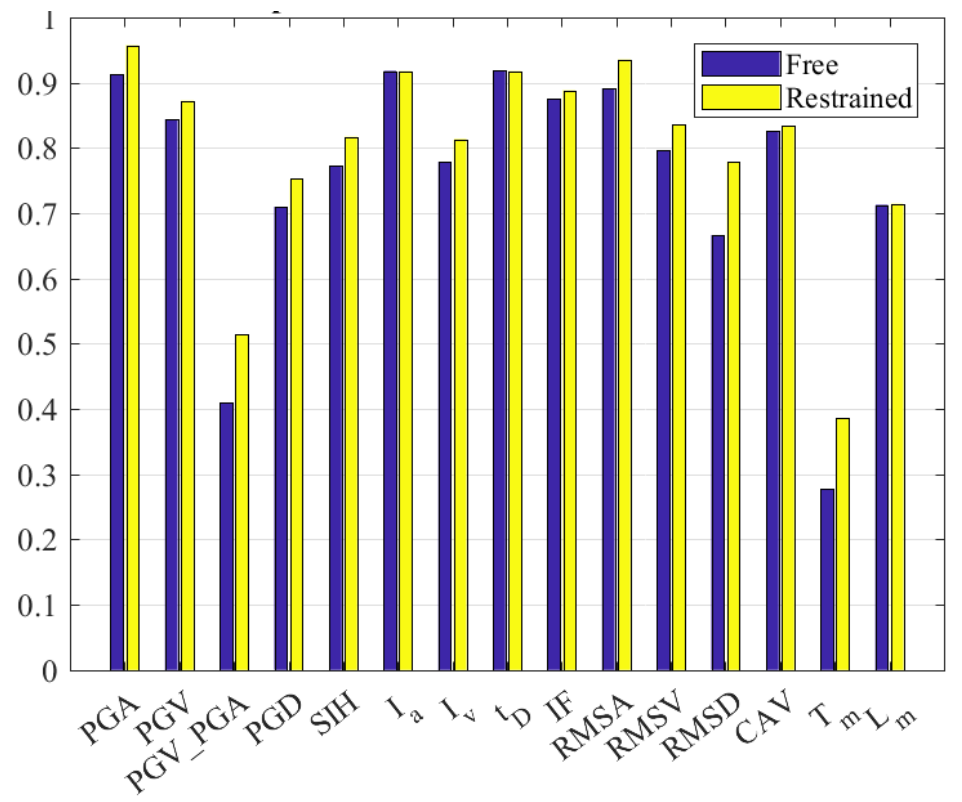

(b)

Figure 8. San Filippo church (SFILCH): Pearson's (a) and Spearman's (b) coefficients. 


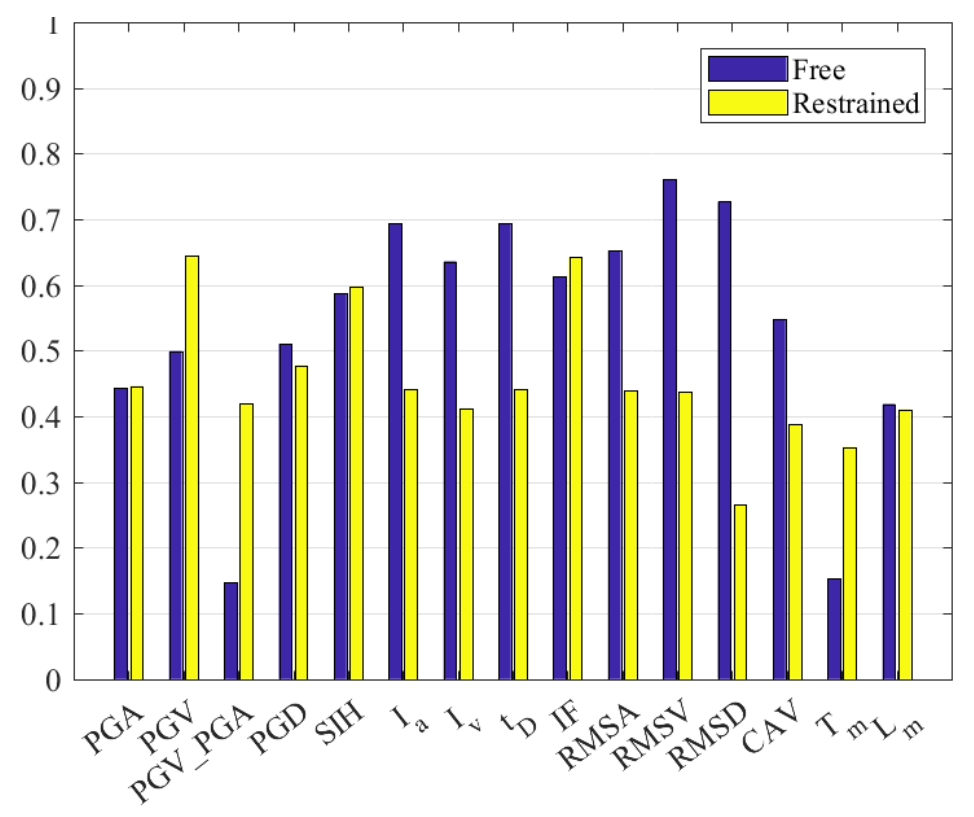

(a)

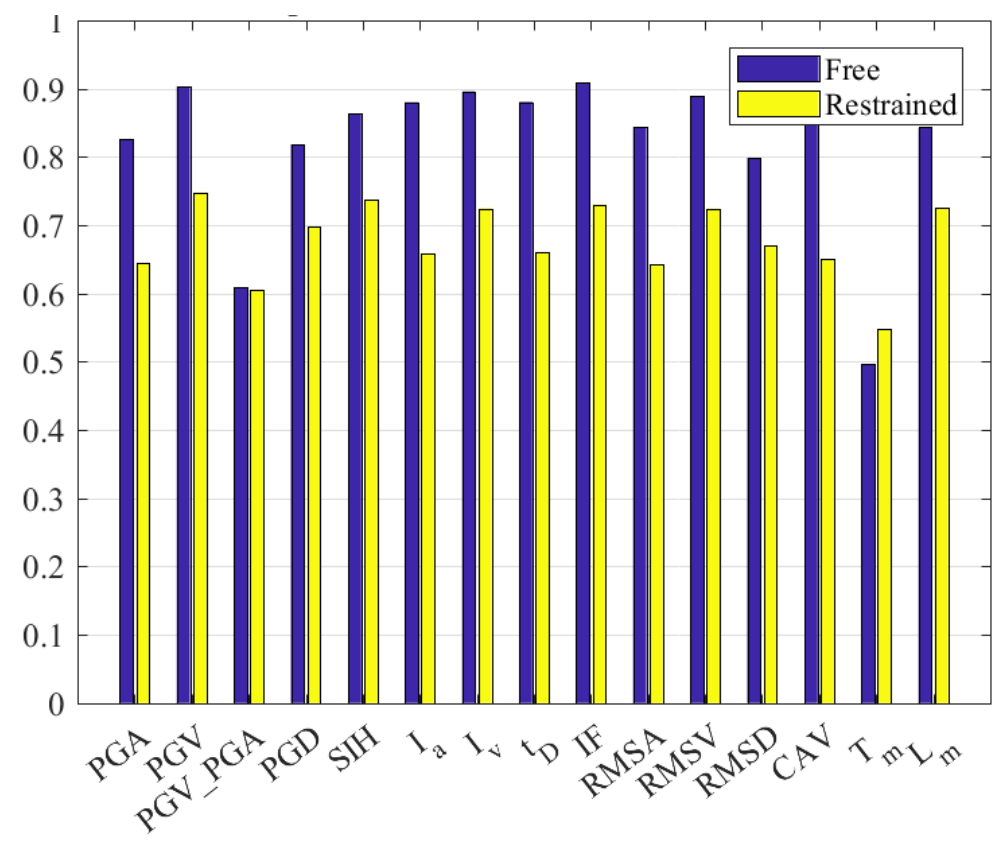

(b)

Figure 9. Santa Maria in Via church (SMVCH): Pearson's (a) and Spearman (b) coefficients.

\section{FRAGILITY CURVES FOR FREE WALLS IN ONE-SIDED MOTION}

\subsection{Univariate fragility curves}

This paragraph presents univariate fragility curves (FCs) that allow to understand how the probability changes depending on the considered limit state for the façades in one-sided motion. The reliability analysis is performed by obtaining FCs from Equation (5), expressing the conditional probability for the serviceability limit states $L S 1$ (limited rocking, $\left.\left(\vartheta_{\max } / \alpha\right)_{l i m}=0.1\right), L S 2$ (moderate rocking, $\left.\left(\vartheta_{\max } / \alpha\right)_{l i m}=0.4\right)$ and $L S 3$ 
(near-collapse, $\left.\left(\vartheta_{\max } / \alpha\right)_{\text {lim }}=1.5\right)$ through a standard cumulative distribution function. In the curves, probability is plotted against the more relevant Intensity Measures (Section 4). Figure 10 shows the univariate FCs for the façades in one-sided motionfor the four more relevant IMs, corresponding to the greater values of Pearson's coefficients.

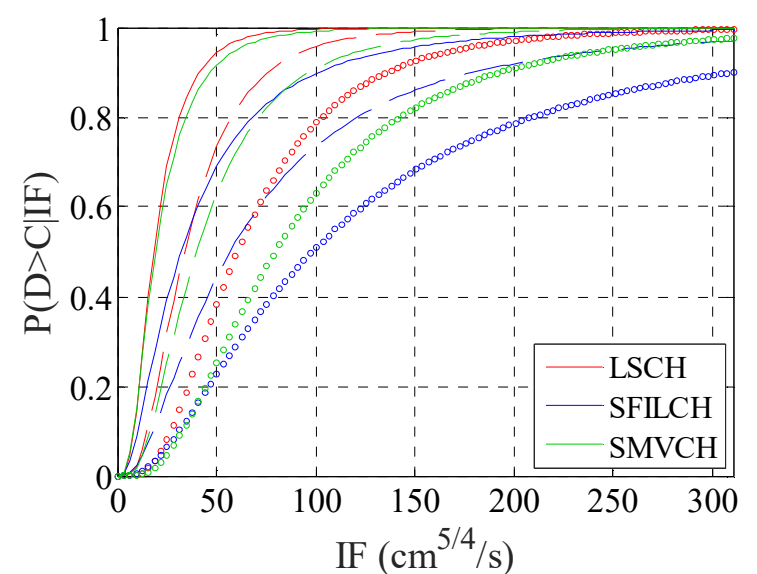

(a)

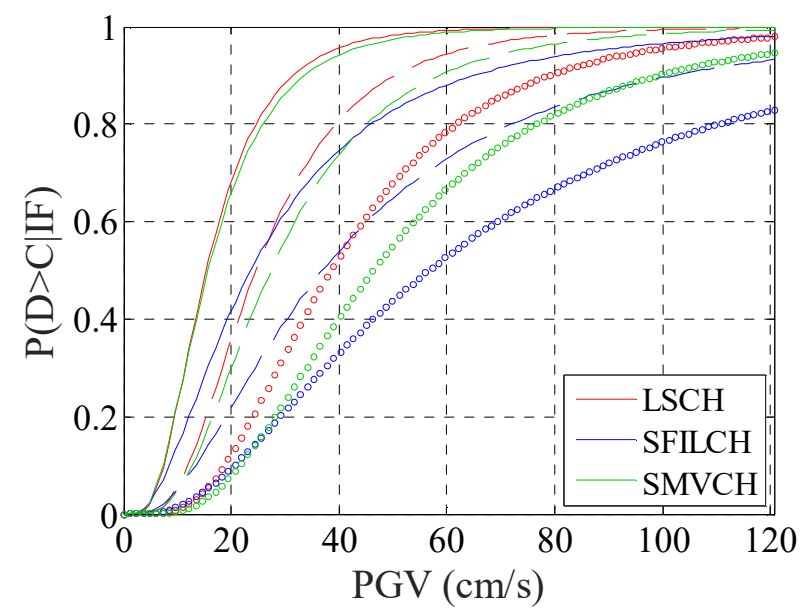

(c)

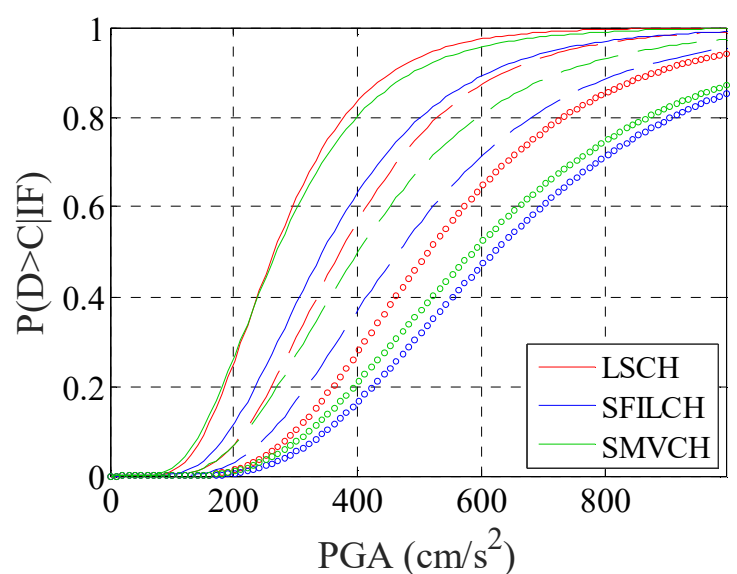

(b)

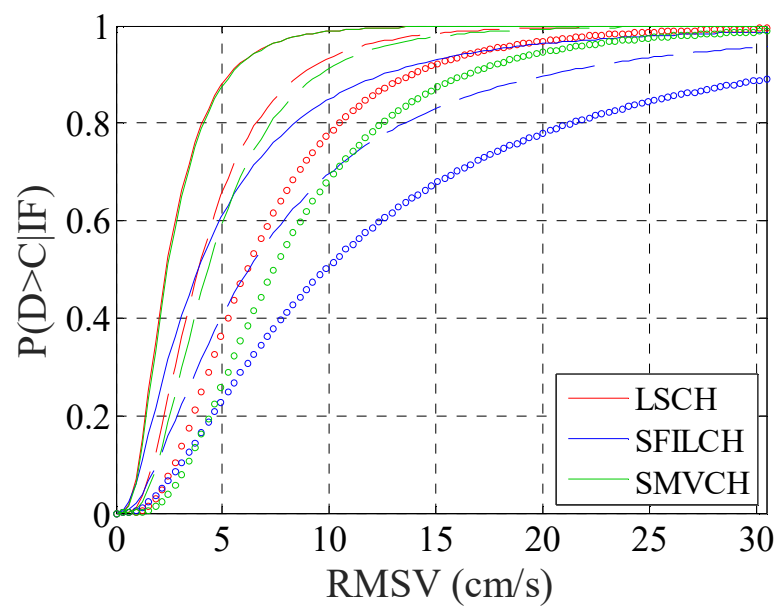

(d)

Figure 10. Univariate fragility curves for one-sided motion of the three façades with IMs corresponding to the greater Pearson's coefficients: continuous line: LS1, dashed line: LS2, dotted line: LS3.

It is interesting to notice that, for the first limit state LS1 $\left(\left(\vartheta_{\max } / \alpha\right)_{\lim }=0.1\right)$ the behavior of San Michele (LSCH) and Santa Maria in Via (SMVCH) are very similar (Figure 10). Indeed, they have similar slenderness ratio (respectively 0.7 and 0.6) but the inertia moment of Santa Maria in Via's façade is two orders of magnitude greater. As expected, this causes a reduction (although slight) of the probability of exceedance in all the limit states of SMVC with respect to LSCH. In fact, as stated in [50], the role of the rotational inertia moment is crucial for the stability of the rocking block. Nevertheless, in some cases the higher stability of the façade with highest inertia moment get closer to the others (e.g. when the considered IM is PGV or RMSV, Figure 10c,d). This is due to the fact that the rebound effect, more relevant being the compression stiffness of the sidewalls much higher, is such that motion is amplified. For the same reason, the façade with lower compression stiffness (SFILCH) is generally the safest among the three cases, in particular for the near collapse limit state (Figure 10c,d). Another justification for this response is that this façade is also that with higher slenderness ratio (0.10), and therefore more stable [2]. Despite this stability, SFILCH was actually the only collapsed case, but this evaluation did not take into account how the structure filtered the acceleration timehistories, since the rotational hinge of the base wall is not on the ground (Figure 3). Therefore, more realistic 
assumptions (considering a magnification factor of the seismic input) have been made for SFILCH and results discussed in 6.3 .

\subsection{Bivariate fragility curves}

Bivariate FCs are also considered and obtained from the calculation of the structural demand through Equations (10)-(11). Bivariate FCs are often more significant than univariate curves: the superiority of bivariate IMs over univariate IMs was also discussed in [25]. The most efficient IMs are selected as those corresponding to the lowest dispersion coefficients $\beta_{D \mid I M}$, usually those where energy-based parameters are coupled with velocity based parameters. This result is more than reasonable: the effects of a time history are due to the combination of a cumulative parameter, calculated on the entire time range, with the effects of a cinematic peak. Some bivariate FCs are reported for the free case of LSCH in Figure 11. Obviously, the probability associated to the yielding limit state (Figure 11b) is higher than that of the limit states from 1 to 3 (Figure 11a). To consider the Fajfar Index with the Cumulative Absolute Velocity (Figure 11a,b) or with Arias Intensity (Figure 11e,f) is more in favour of safety than consider it associated with the RMSA (Figure 11c,d).

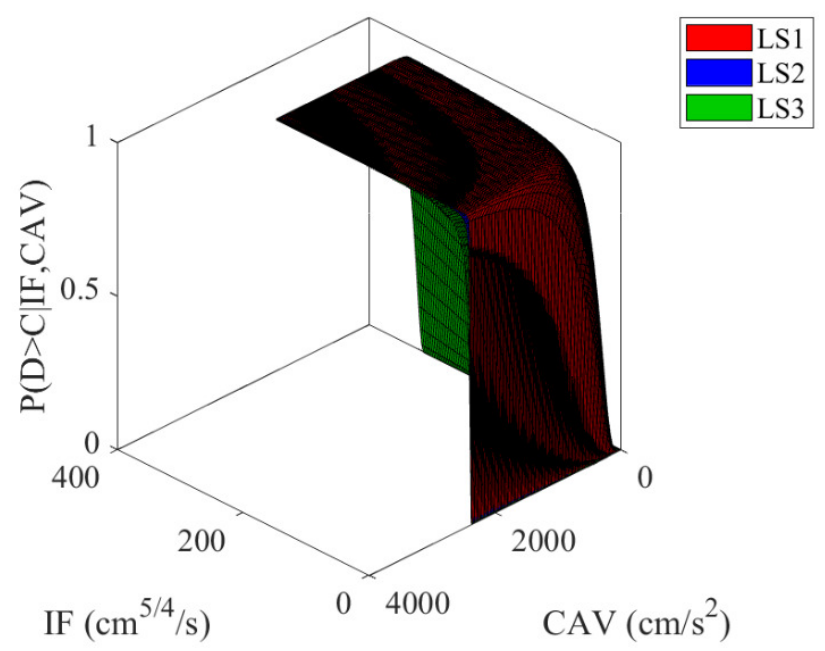

(a)

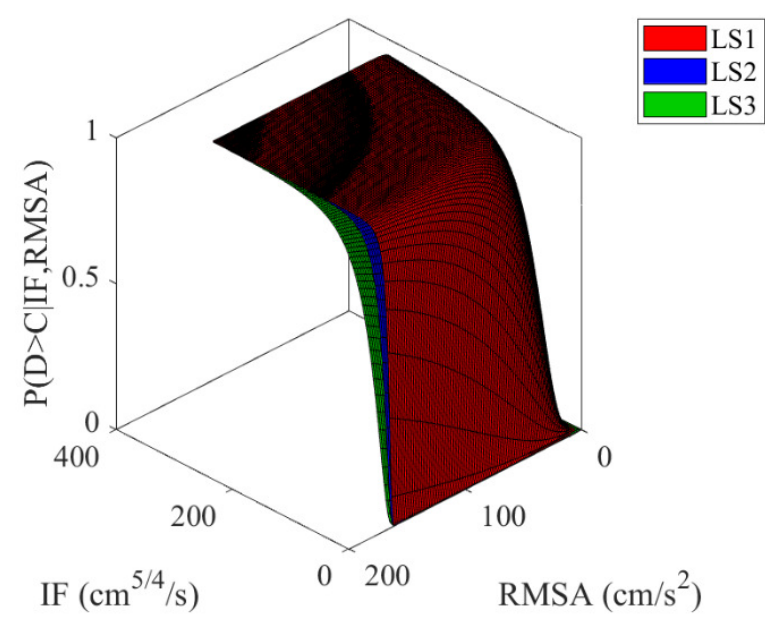

(c)

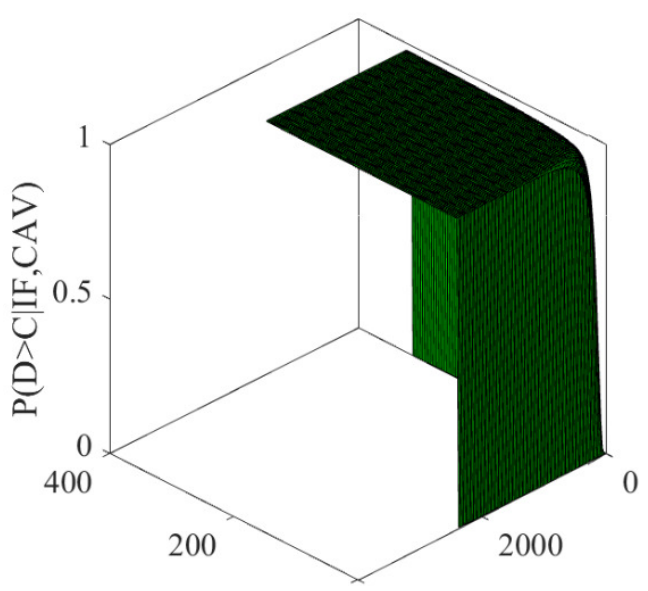

$$
\operatorname{IF}\left(\mathrm{cm}^{5 / 4} / \mathrm{s}\right) \quad 0 \quad 4000 \quad \operatorname{CAV}\left(\mathrm{cm} / \mathrm{s}^{2}\right)
$$

(b)

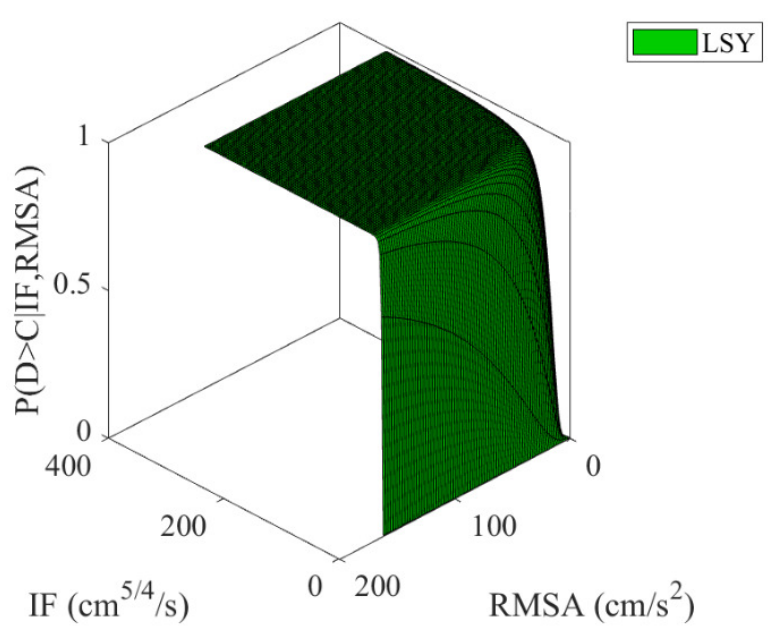

(d) 


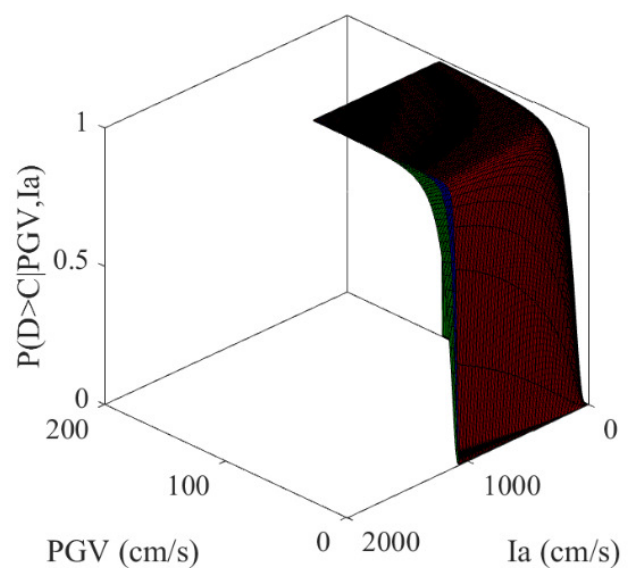

(e)

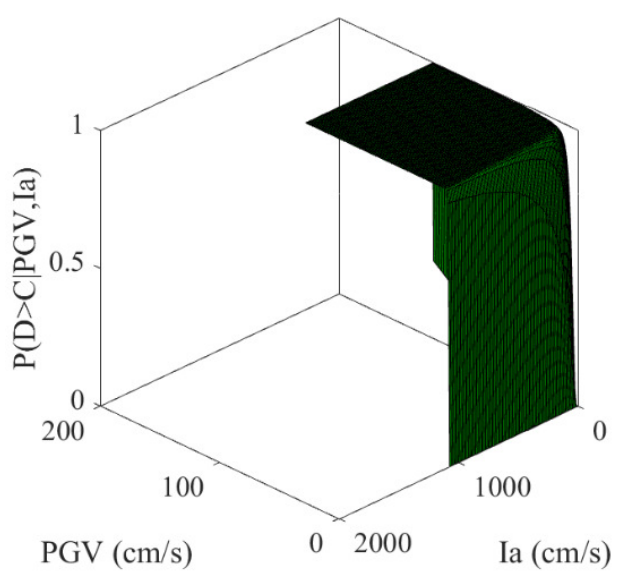

(f)

Figure 11 Bivariate fragility curves of LSCH, free case, for the most efficient IMs: LS1, LS2 and LS3 (a) and LSY (b).

For the same case, the bivariate FCs for the fourth more efficient IMs is shown in together with the regression diagram (Figure 12).

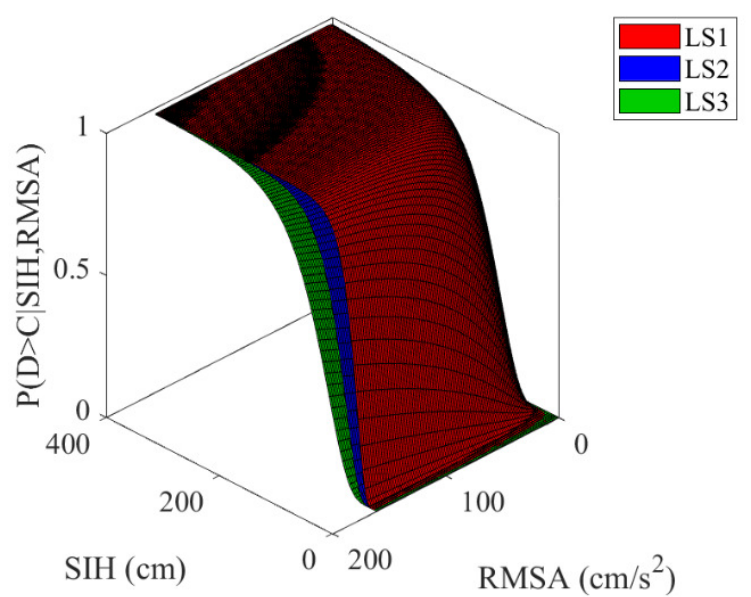

(a)

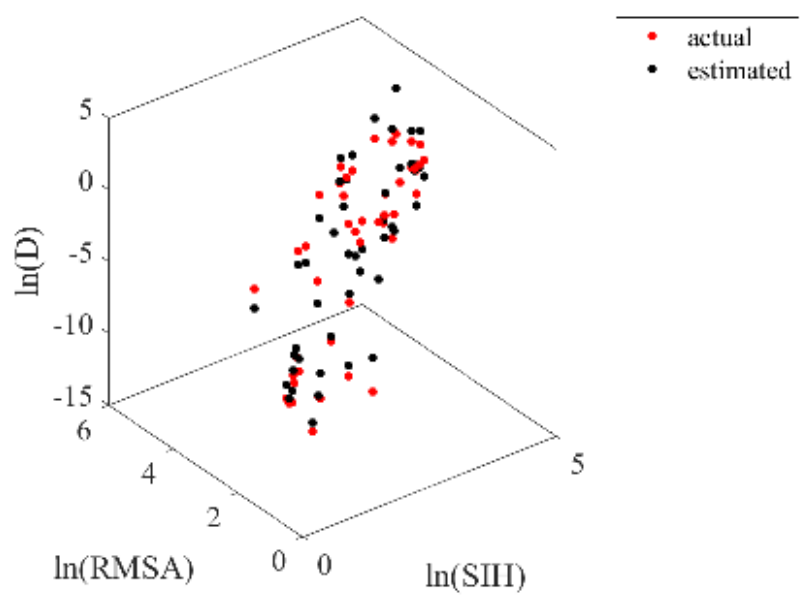

(b)

Figure 12 Bivariate fragility curve (a) of $\mathrm{LSCH}$, free case and corresponding regression diagram (b).

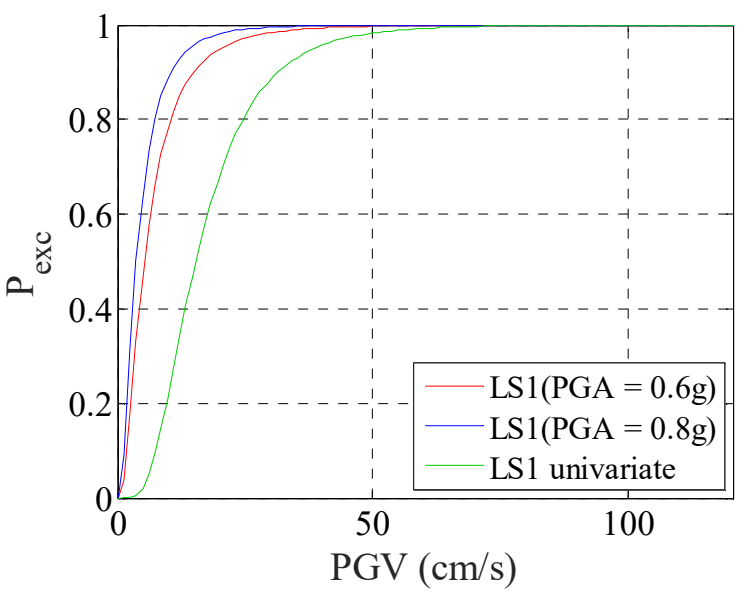

(a)

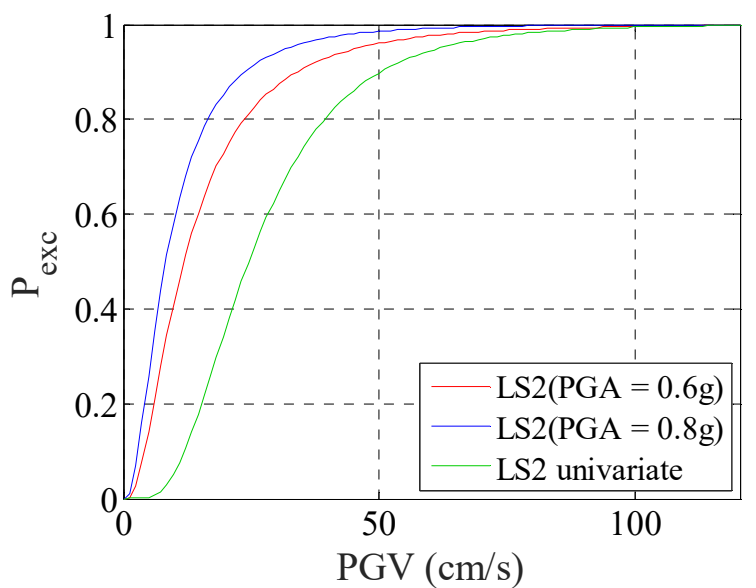

(b) 


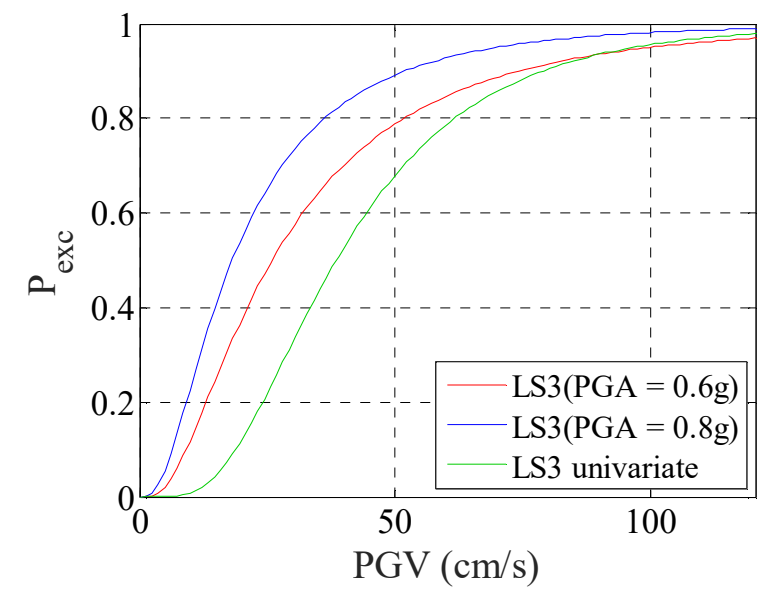

(c)

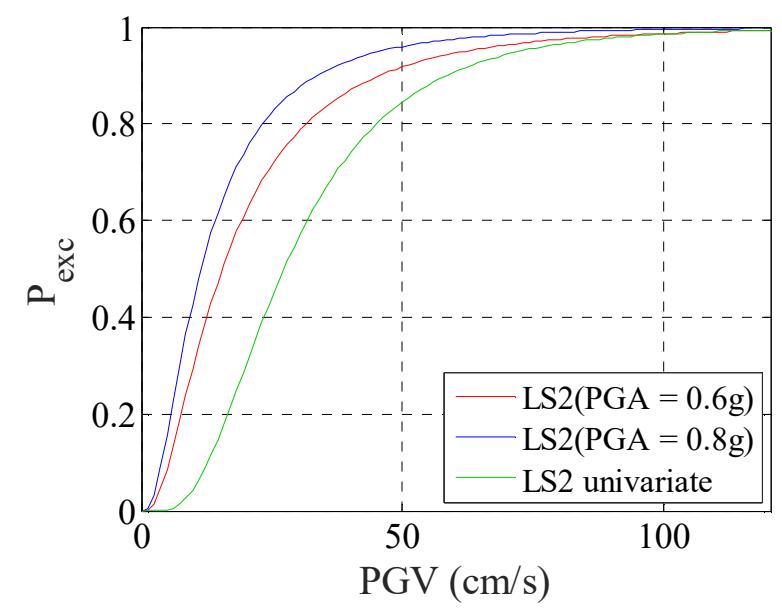

(e)

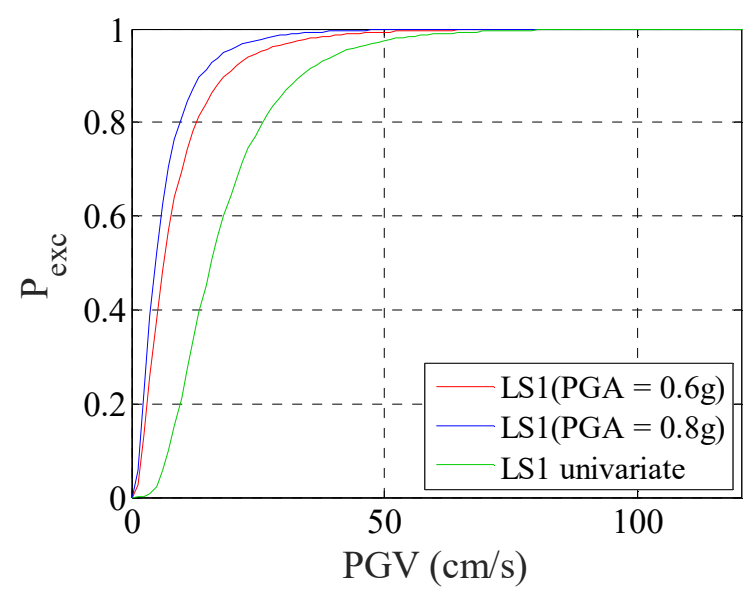

(d)

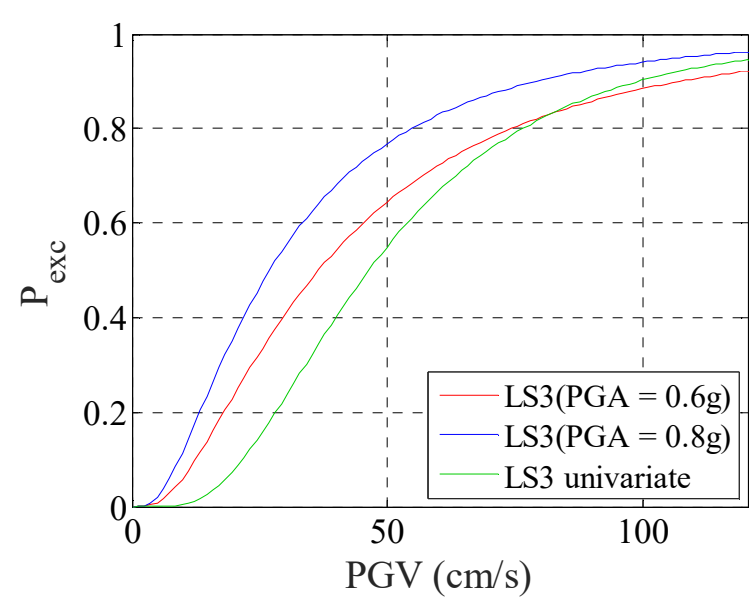

(f)

Figure 13 Comparison of bivariate with univariate fragility curves for different PGA values - LSCH free in one-sided motion, LS1 (a), LS2 (b), LS3 (c); - SMVCH free in one-sided motion, LS1 (d), LS2 (e), LS3 (f).

It is useful to compare univariate and bivariate FCs to confirm the superiority of bivariate FCs. Let us consider the three limit states from LS1 to LS3, where the "univariate" case refers to the unique evaluation of PGV. In Figure 13, besides the univariate FCs also the bivariate FCs are shown with specific values of PGA (e.g. $0.6 \mathrm{~g}$ and $0.8 \mathrm{~g}$ ). The univariate curve underestimates the probability of exceedance with respect than the bivariate curves. For instance, for LS1 (LSCH, Figure 13a), considering an earthquake of PGV $=10 \mathrm{~cm} / \mathrm{s}$, the probability of exceedance given by the univariate curve is $20 \%$. This value is four times higher when a PGA $=0.6 \mathrm{~g}$ is taken into account. Moreover, the univariate curves are not capable to offer any information dependent on the level of other IMs. Yet, PGA is in this case extremely relevant as produces significant changes in the probability of exceedance for the same value of PGV. This occurs for serviceability limit states (Figure 13a,b,d,e) to a greater extent than for near-collapse limit states (Figure 13c,f). . Finally, the univariate FC is flatter $\mathrm{c}$ than the bivariate curves, which indicates higher uncertainty. 


\section{FRAGILITY CURVES FOR FREE AND RESTRAINED WALLS IN YIELDING LIMIT STATE}

In this section, the fragility curves in the yielding limit state LSY as defined in $\S 2.3$ are obtained with the purpose of comparing one sided free and restrained configurations. First, univariate FCs are reported, and secondly bivariate FCs are shown to understand the difference of considering them or the former ones in the safety assessment.

\subsection{Univariate fragility curves}

When IMs are individually considered, the consequent univariate fragility curves are useful since comparison between one sided free and one sided restrained cases is straightforward. Here, only the yielding limit state is considered, because once yielding is attained by the steel tie-rods (whose characteristics are reported in Table 3 ), the analysis stops. Some of the obtained fragility curves are reported in Figure 14 for the more relevant IMs, the same adopted in 5.1. There are not substantial differences with the results illustrated for the limit states of limited, moderate rocking and near-collapse condition when no tie-rods are taken into account. Indeed, the façades with similar slenderness perform again similarly (Figure 14). By contrast, the façades with closer inertia moment and radius vector $R$ (namely SFILCH and LSCH) equivalently behave (red, LSCH and blue, SFILCH, continuous curves of Figure 14) when the tie-rods are assumed. It is interesting to notice that the stiffness of the tie-rods is of a similar value (about $2 \mathrm{E} 7 \mathrm{~N} / \mathrm{m}$, Table 3 ), but its height with respect to the rocking hinge is doubled for LSCH. In this case, the improvement obtained (reduction of probability) is more relevant for high values of Intensity Measures (e.g. for PGV $>40 \mathrm{~cm} / \mathrm{s}$, Figure 14). When the block is already safe in free conditions (for low values of IM), the inclusion of a restraint does not influence the response and does not sensitively reduce the attainment of the limit state. Seldom, the restrained condition gives higher response peaks than the free case, due to resonance effects of vibration period associated to the modified system.

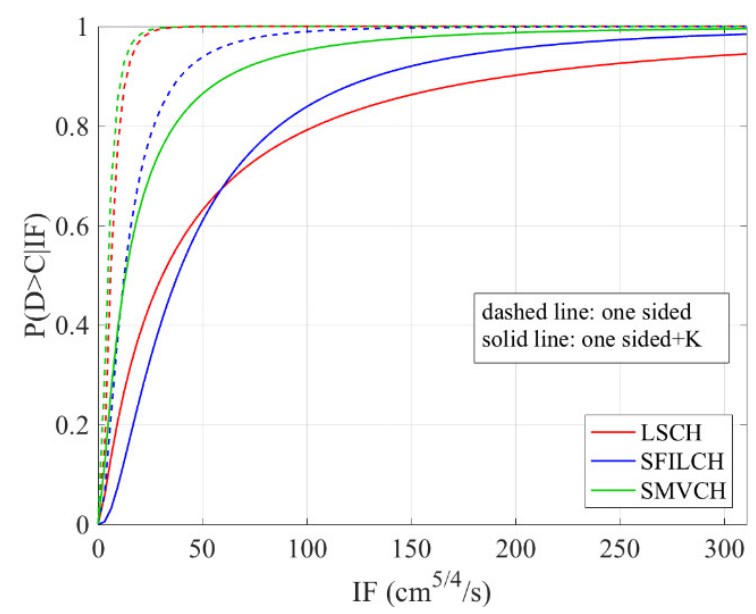

(a)

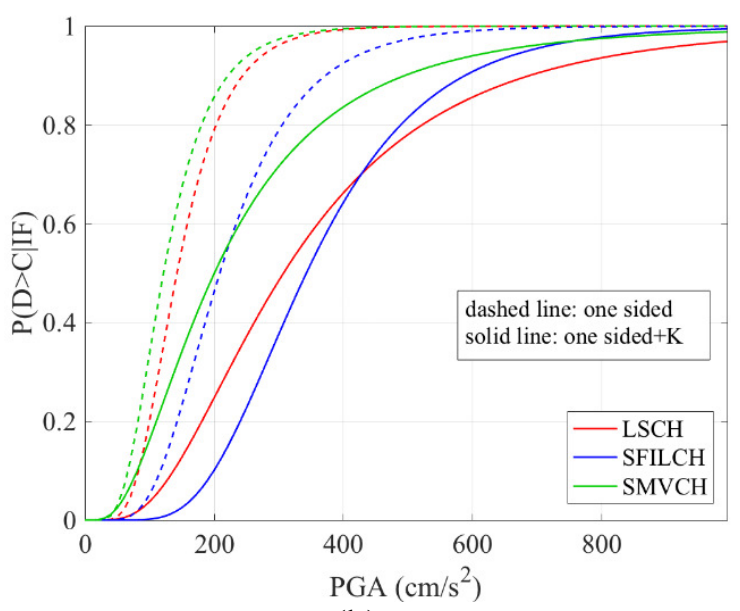

(b) 


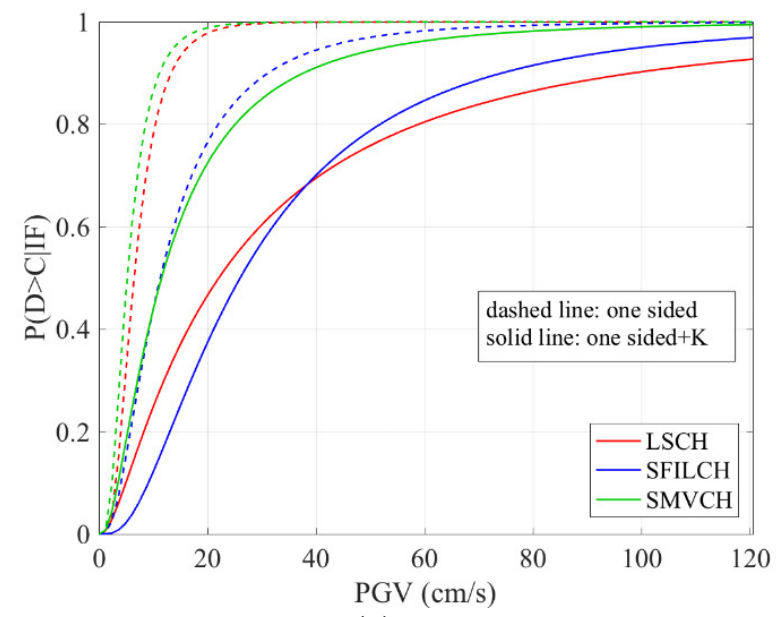

(c)

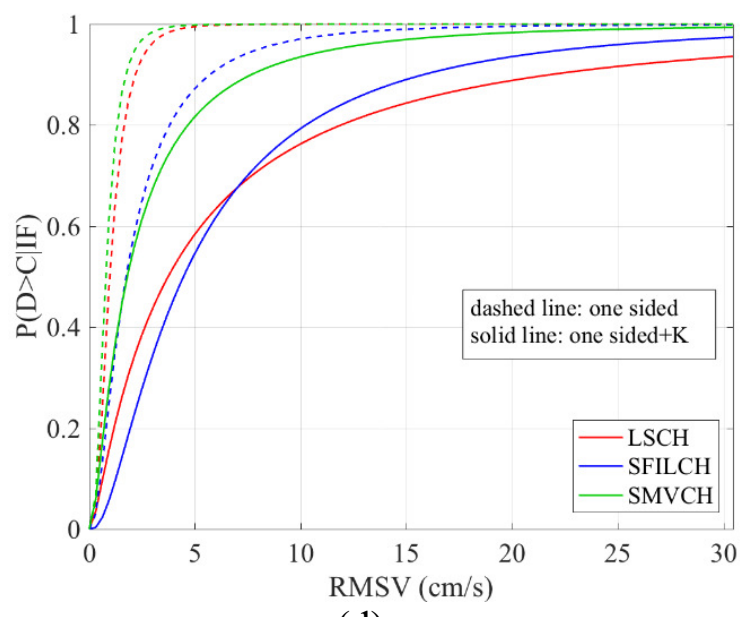

(d)

Figure 14 Univariate fragility curves associated to yielding limit state for free and restrained façades.
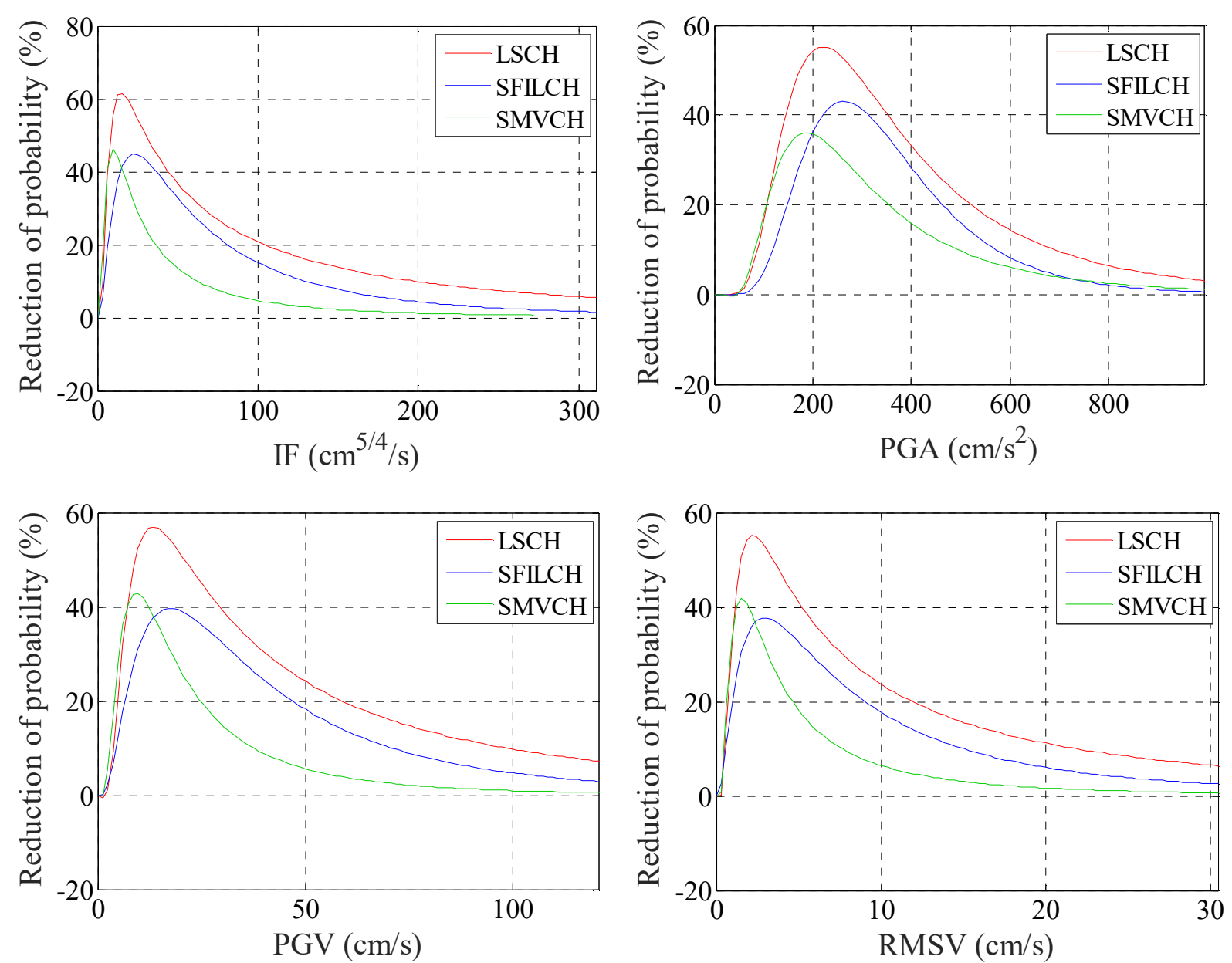

Figure 15 Reduction of conditional probability from univariate FCs associated to yielding limit state.

An advantageous diagram to estimate the amount of improvement given by the anti-seismic device is that where the reduction of conditional probability, expressed as percentage, is plotted against the IM. This helps to understand to what extent the anti-seismic device can be beneficial or detrimental (in case of resonance conditions and amplifications of motion) for fixed earthquake intensities. The reductions of probability corresponding to Figure 14 are shown in Figure 15. It is relevant to observe that the maximum reduction of 
probability is similar for the velocity based IMs (IF, PGV and RMSV), being about $40 \%$. Peaks of about $60 \%$ are obtained in the case of intermediate slender and inertia moment (LSCH). Also when PGA is considered, a significant reduction of probability occurs for all cases. This result is relevant as the restraint of a masonry façade with simple tie-rods of common stiffness [51] is clearly beneficial for the wall stability. The reduction of probability of exceedance in case of anti-seismic device is evident for medium-high intensity earthquakes. In fact, e.g. for $10<\mathrm{PGV}<30 \mathrm{~cm} / \mathrm{s}$, or for $180 \mathrm{~cm} / \mathrm{s}^{2}<\mathrm{PGA}<380 \mathrm{~cm} / \mathrm{s}^{2}$, one has a reduction of at least $30 \%$ of probability of exceedance (for LSCH and SFILCH). For $10<\mathrm{PGV}<25 \mathrm{~cm} / \mathrm{s}$, or for $150 \mathrm{~cm} / \mathrm{s}^{2}<\mathrm{PGA}<350 \mathrm{~cm} / \mathrm{s}^{2}$, one has a reduction of at least $20 \%$ of probability of exceedance for all the façades. Therefore, the level of improvement obtained for the façade with higher probability in the free case, the most slender one, is slightly lower when tie-rods are considered. To conclude, the graphs showing the reduction of probability can be practical for engineers aimed at defining a risk reduction level with the adoption of an effective horizontal restraint.

\subsection{Bivariate fragility curves}

The comparison of bivariate fragility curves is made in this paragraph between the case of unrestrained and the case of restrained façade. Some examples of reduction of probability curves are shown in Figure 16. In general, a good reduction of probability is obtained when PGA is considered as one of the two IMs of the bivariate curves. Moreover, it is observed that, for instance, to consider as second IM RMSA instead of IF is in favour of safety. However, a strong reduction, from $20 \%$ to $80 \%$, occurs for low-medium intensity earthquakes.
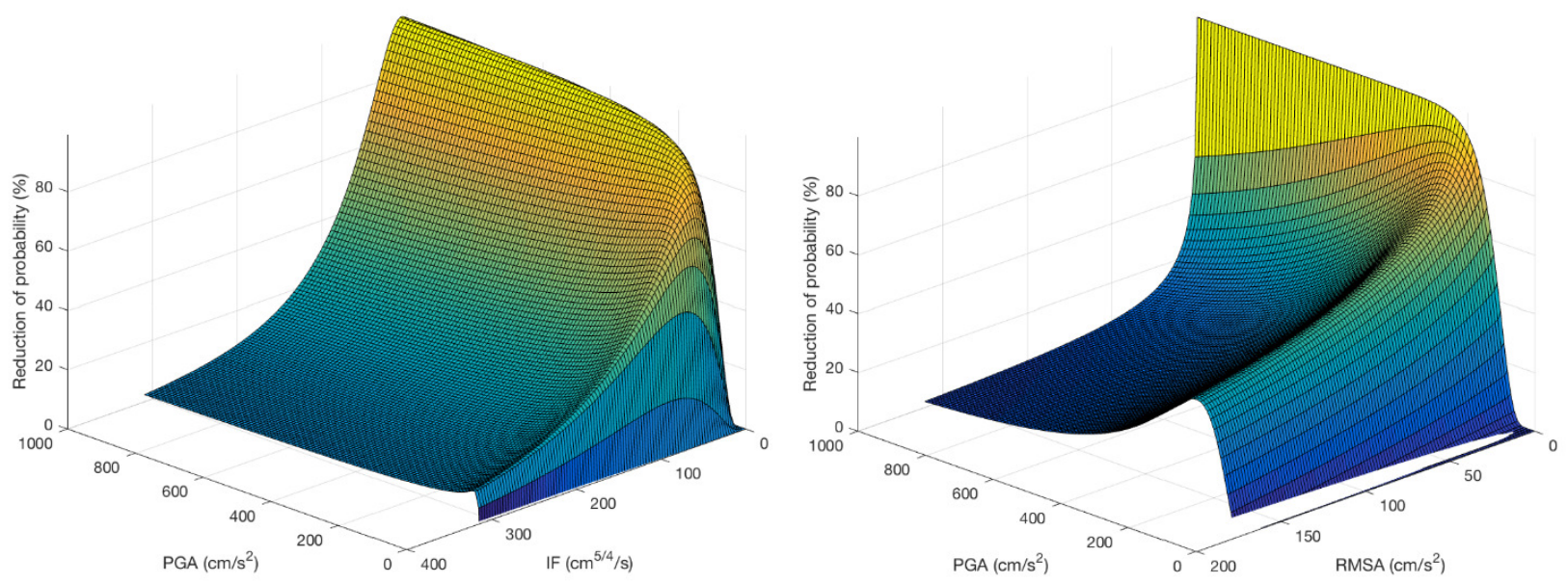

Figure 16 Reduction of conditional probability from univariate FCs associated to yielding limit state $(\mathrm{LSCH})$. 


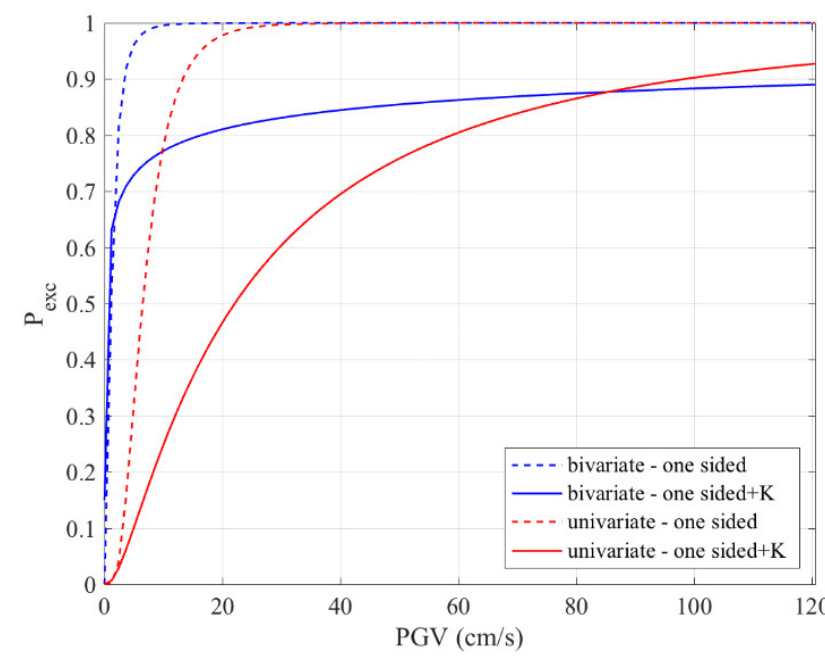

(a)

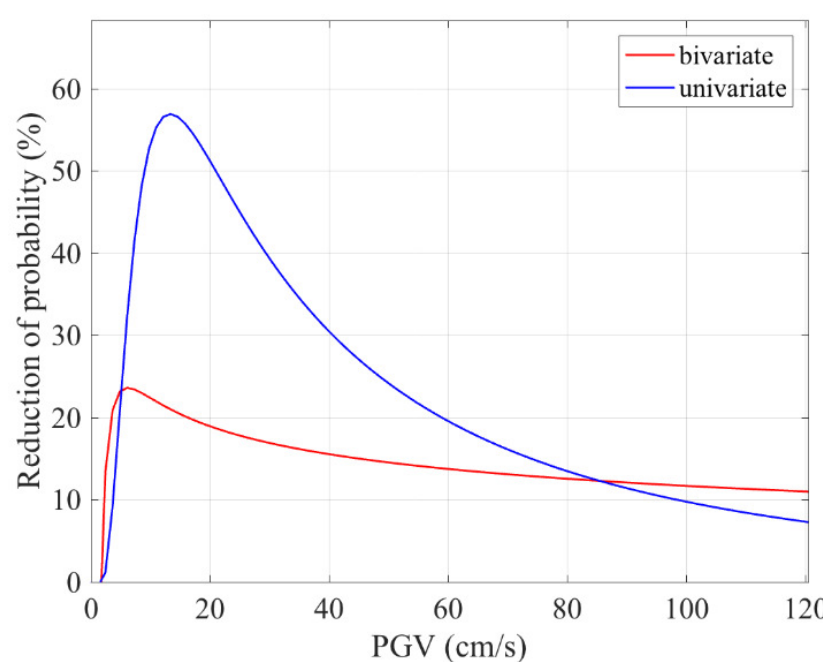

(b)

Figure 17 Comparison of univariate $\mathrm{FC}$ with bivariate $\mathrm{FC}(\mathrm{PGA}=0.6 \mathrm{~g})(\mathrm{a})$, corresponding reduction of probability $(\mathrm{LSCH})$.

The possibility of underestimation of probability of exceedance of the limit state considering univariate with respect to bivariate curves is again confirmed in restrained conditions (Figure 17). For medium intensity earthquakes, the reduction of probability is strongly overestimated when only PGV is taken into account. When, PGA $(=0.6 \mathrm{~g})$ is considered in addition to PGV, the reduction of probability drops down (red curve of Figure 17b). The maximum peak of reduction passes from about $55 \%$ to $25 \%$. This confirms that, as discussed in 5.2, the consideration of bivariate fragility curves allows a more complete information regarding the stochastic estimations. In addition, only a bivariate FC permits to combine an energy based IM with a cinematic based IM, so achieving a more reasonable measure of the time history effects.

\subsection{Comparison of stochastic analysis with actual results}

Some comparisons can be made between the results obtained from the analysis and the actually occurred damages in the churches. In particular, so far the unmodified acceleration time-histories have been applied as input signals for the three façades. No modification has been made in order to make comparisons of univariate and bivariate FCs with the same ground motions. Nevertheless, SFILCH has the horizontal rocking hinge at $14 \mathrm{~m}$ from the ground (Figure 3). Therefore, the filter effect exerted by the substructure has to be examined. By considering the indications given by the Italian Standards [36], an increment of $27 \%$ of the acceleration time-histories has to be taken into account. With this value, additional analyses have been performed by increasing the acceleration values of all the seismic records only for SFILCH. The obtained fragility curves are reported in Figure 18a,b, where the outcomes are also compared with the FCs valid for SMVCH and LSCH. In effect, it is clear that the probability of exceedance associated to SFILCH more realistically modelled strongly increases by considering the magnification factor of 1.27 . This could explain why the upper portion of façade actually collapsed and the same did not occur for the other façades. The increased probability of collapse is particularly evident for PGA (Figure 18a) and for PGV in the domain of low intensity values (Figure 18b). The probability values overcome those of $\mathrm{LSCH}$, which resulted to be the most vulnerable case. In effect, this façade showed an incipient overturning with a detachment from sidewalls particularly visible from inside (Figure $2 \mathrm{~b}$ ). The seismic shock for which the SFILCH façade collapsed, recorded in the station closest to Camerino (Matelica, MTL), has PGA $=240 \mathrm{~cm} / \mathrm{s}^{2}$, e PGV $=11.68$ $\mathrm{cm} / \mathrm{s}$ [48]. In fact, for this value the probability of collapse is higher, although slightly, than the other cases. Finally, the analysis is performed for the restrained case (with steel tie-rods, Table 3) again assuming a 
magnification factor of the seismic input of 1.27. It is observed that the probability of exceedance of the yielding limit state strongly decreases (Figure 18c), and the peak of reduction is higher than $30 \%$ for $5<\mathrm{PGV}<30 \mathrm{~cm} / \mathrm{s}$ (Figure 18d). Therefore, the so designed steel tie rods could have caused an undeniable improvement of response of the façade, potentially avoiding its collapse.

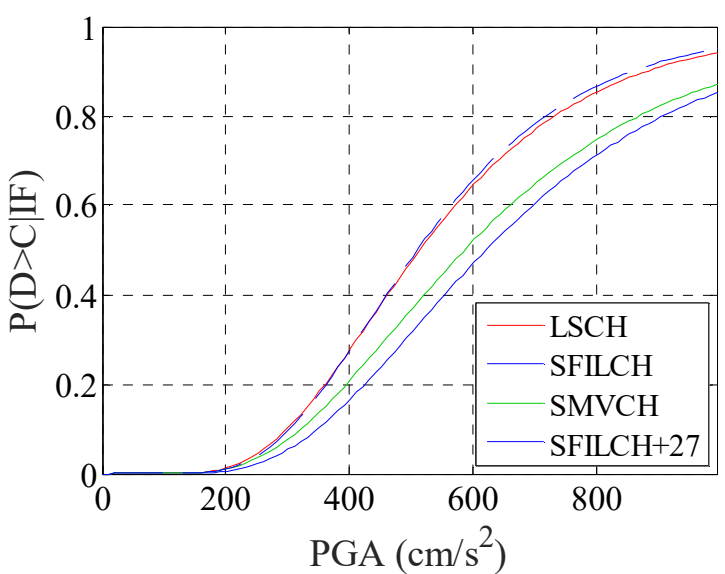

(a)

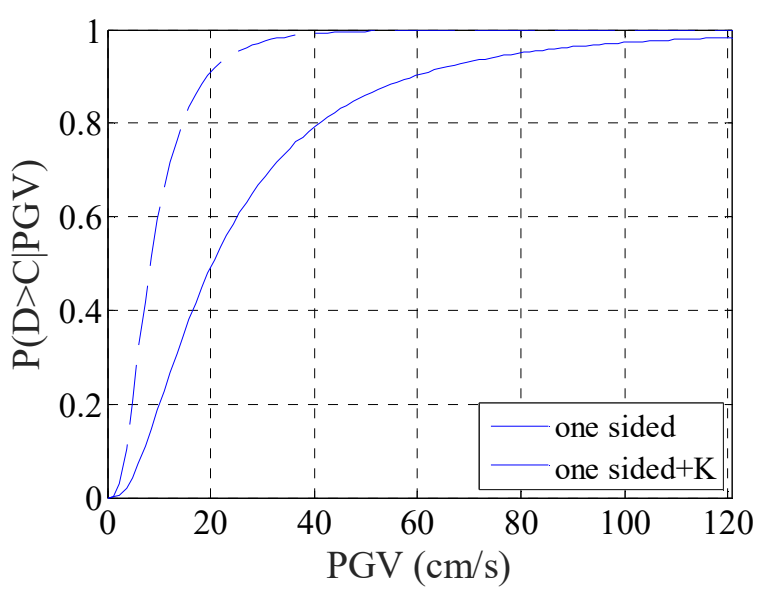

(c)

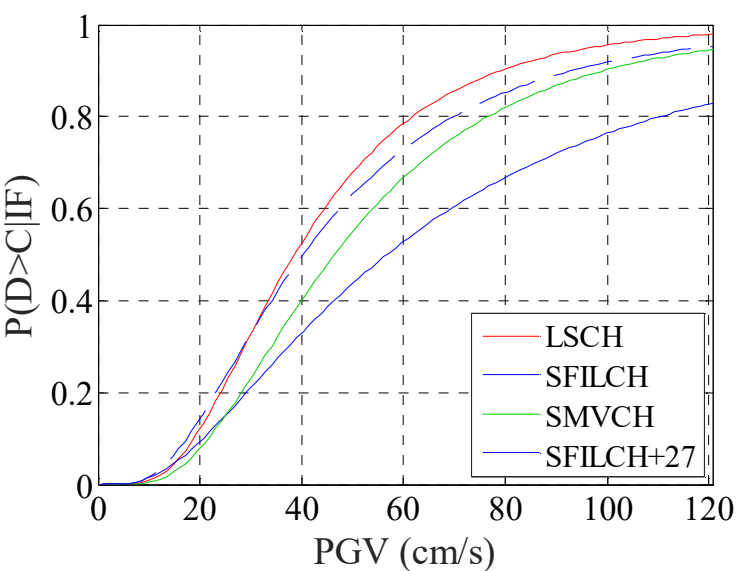

(b)

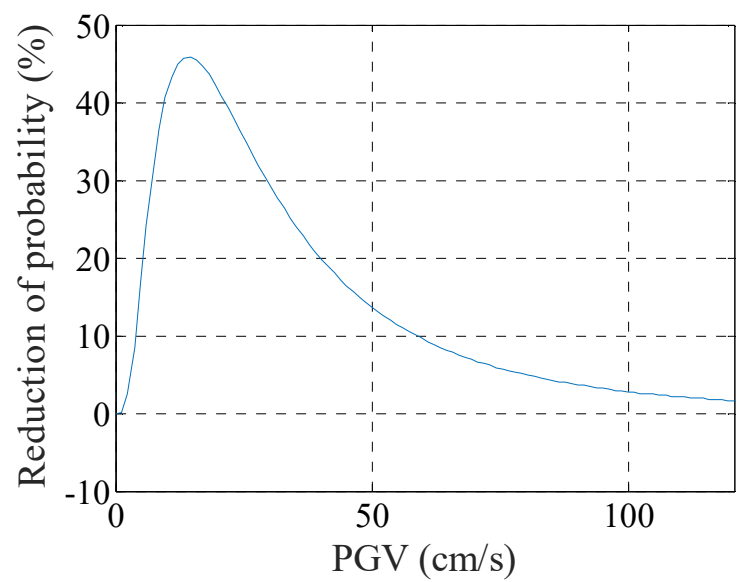

(d)

Figure 18 Comparison of univariate FCs with unscaled acceleration time-histories with FC with amplified acceleration time history $(\mathrm{a}, \mathrm{b})$ with magnification factor 1.27 ; variation of probability of exceedance of limit states in case of restraints (c) and corresponding reduction of probability (d) (acceleration time-histories amplified by 1.27$)$.

\section{CONCLUSIONS}

In this paper, a probabilistic approach for defining the stability of free and restrained masonry rocking façades is presented. The purpose is to stochastically define the level of improvement achieved with any anti-seismic device of a specific stiffness, in terms of reduction of probability of exceedance of a certain limit state. Indeed, especially when there are not negligible uncertainties about input motion, as usually occurs, a probabilistic analysis is recommended rather than a deterministic one. The additional restraints reproduce the common steel 
tie-rods usually adopted as strengthening techniques for impeding or limiting the out-of-plane behavior of masonry structures. First, the calculation of correlation coefficients has been performed for three typical samples of masonry façades of monumental buildings. Independently from the considered façade and the boundary condition, the linear correlation defines the most relevant IMs, which are the velocity-based parameters, in particular the Fajfar Index and Peak Ground Velocity, but also PGA. The less representative IMs are generally the Root Mean Square Displacements RMSD, Peak Ground Displacement PGD, mean period $\mathrm{T}_{\mathrm{m}}$ and the characteristic length scale $\mathrm{L}_{\mathrm{m}}$. The higher differences between the case of free and restrained façade in the correlation are obtained for less representative IMs. Instead, differences are negligible for the Pearson's coefficients associated to the more relevant IMs, making the analysis in retrofitted configuration reliable.

For what concerns the fragility curves without horizontal restraints, a higher compression stiffness of the sidewalls implies higher probability of exceedance. This is due to an amplified motion associated to a more marked rebound effect. The most efficient IMs are selected as those corresponding to the lowest dispersion coefficients $\beta_{D \mid I M}$, usually those where energy-based parameters (CAV, RMSA, Ia) are coupled with velocity based parameters (mainly PGV). It corresponds to the fact, physically reasonable, that a time history of motions is identified through two categories of data: cumulative energy on the entire history and peak cinematic values on a specific instant.

As expected, the case with lower conditional probability is the stockier one, in particular for the near-collapse limit state. If the slenderness of the façades is similar, a higher rotational inertia has a positive effect in the stability of the wall, giving lower probability of exceedance of all the limit states. The comparison of univariate and bivariate FCs confirms the superiority of bivariate FCs. Indeed, often the univariate curves sensitively underestimate the probability of exceedance with respect than the bivariate curves. Moreover, the univariate curves are not capable to offer any information dependent on the level of other IMs. In addition, only a bivariate FC permits to combine an energy based IM with a cinematic based IM, so achieving a more reasonable measure of the time history effects.

When horizontal restraints are taken into account, an advantageous diagram to estimate the level of improvement given by the anti-seismic device is that where the reduction of conditional probability, expressed as percentage, is plotted against a specific IM. This helps to understand, in a stochastic perspective, to what extent the anti-seismic device can be beneficial or detrimental (in case of resonance conditions and amplifications of motion) for fixed earthquake intensities. In the considered examples, the maximum reduction of probability is similar for the velocity based IMs (IF, PGV and RMSV), being about $40 \%$. This result is relevant as the restraint of a masonry façade realized with simple tie-rods of common stiffness is clearly beneficial for the wall stability. Moreover, the reduction of probability of exceedance in case of anti-seismic device is evident for medium-high intensity earthquakes. Finally, the possibility of overestimation of the probability of exceedance of the yielding limit state considering univariate with respect to bivariate curves is again confirmed in restrained conditions for low-medium intensity earthquakes.

\section{ACKNOWLEDGEMENTS}

The authors thank the sponsorship of the Italian Department of Civil Protection, in the framework of the RELUIS Project - Masonry Structures (2017) and Eng. Fabio Solarino for helping in the calculations. 


\section{REFERENCES}

[1] Casapulla, C., Giresini, L., Sassu, M., Lourenço, P.B., "Rocking and kinematic approaches of masonry walls: state of the art and recent developments," Buildings, 2017.

[2] L. Sorrentino, D. D’Ayala, G. de Felice, M. C. Griffith, S. Lagomarsino, and G. Magenes, "Review of Out-of-Plane Seismic Assessment Techniques Applied To Existing Masonry Buildings," Int. J. Archit. Herit., vol. 11, no. 1, pp. 2-21, 2017.

[3] R. E. Scholl, "Statistical analysis of low-rise building damage caused by the San Fernando earthquake," Bull. Seismol. Soc. Am., vol. 64, no. 1, p. 1, 1974.

[4] B. Lizundia, "Damage to Unreinforced Masonry Buildings in the October 17, 1989 Loma Prieta Earthquake," 1991.

[5] N. . Ismail, M. C. Griffith, and J. M. Ingham, "Performance Of Masonry Buildings During The 2010 Darfield (New Zealand) Earthquake," in the Eleventh North American Masonry Conference, 2011.

[6] D. Dizhur, J. Ingham, L. Moon, M. Griffith, A. Schulz, and I. Senaldi, "Performance of Unreinforced Masonry Buildings During the 2010 Darfield (Christchurch, Nz) Earthquake," Aust. J. Struct. Eng., vol. 11, no. 3, pp. 207-224, 2010.

[7] L. Sorrentino, L. Liberatore, L. D. Decanini, and D. Liberatore, "The performance of churches in the 2012 Emilia earthquakes," Bull. Earthq. Eng., vol. 12, no. 5, pp. 2299-2331, 2014.

[8] S. Prajapati, O. AlShawa, and L. Sorrentino, "Out-of-plane behaviour of single-body unreinforcedmasonry wall restrained by a flexible diaphragm," in COMPDYN 2015 - 5th ECCOMAS Thematic Conference on Computational Methods in Structural Dynamics and Earthquake Engineering, 2015, pp. 3127-3138.

[9] L. Giresini and M. Sassu, "Horizontally restrained rocking blocks: evaluation of the role of boundary conditions with static and dynamic approaches," Bull. Earthq. Eng., vol. 15, no. 1, pp. 385-410, 2017.

[10] C. Casapulla and L. U. Argiento, "The comparative role of friction in local out-of-plane mechanisms of masonry buildings. Pushover analysis and experimental investigation," Eng. Struct., vol. 126, pp. 158-173, 2016.

[11] G. W. Housner, "The behavior of inverted pendulum structures during earthquakes," Bull. Seismol. Soc. Am., vol. 53, no. 2, pp. 403-417, 1963.

[12] L. Sorrentino, O. AlShawa, and L. D. Decanini, "The relevance of energy damping in unreinforced masonry rocking mechanisms. Experimental and analytic investigations," Bull. Earthq. Eng., vol. 9, no. 5, pp. 1617-1642, 2011.

[13] F. Graziotti, U. Tomassetti, A. Penna, and G. Magenes, "Out-of-plane shaking table tests on URM single leaf and cavity walls," Eng. Struct., vol. 125, pp. 455-470, 2016.

[14] N. Makris and D. Konstantinidis, "The rocking spectrum and the limitations of practical design methodologies," Earthq. Eng. Struct. Dyn., vol. 32, no. 2, pp. 265-289, Feb. 2003.

[15] C. Casapulla, P. Jossa, and A. Maione, "Rocking motion of a masonry rigid block under seismic actions: A new strategy based on the progressive correction of the resonance response | Il moto sotto sisma del blocco murario: Analisi per progressiva correzione della risposta in risonanza," Ing. Sismica, vol. 27, no. 4, pp. 35-48, 2010.

[16] Takewaki I., Moustafa A., Fujita K., Improving the Earthquake Resilience of Buildings: The Worst Case Approach. London: Springer, 2012.

[17] C. Casapulla, "On the resonance conditions of rigid rocking blocks," Int. J. Eng. Technol., vol. 7, no. 2, pp. 760-771, 2015. 
[18] Nabeshima K., Taniguchi R., Kojima K., Takewaki I., "Closed-form overturning limit of rigid block under critical near-fault ground motions," Front. Built Environ., vol. 2, no. 9, pp. 1-11, 2016.

[19] C. Casapulla and A. Maione, "A simplified equation of motion for free rocking rigid blocks," in Insights and Innovations in Structural Engineering, Mechanics and Computation - Proceedings of the 6th International Conference on Structural Engineering, Mechanics and Computation, SEMC 2016, 2016, pp. 120-126.

[20] C. Casapulla and A. Maione, "Free Damped Vibrations of Rocking Rigid Blocks as Uniformly Accelerated Motions," Int. J. Struct. Stab. Dyn., vol. 17, no. 6, pp. 1-19, 2016.

[21] M. A. Casapulla C., "Critical Response of Free-Standing Rocking Blocks to the Intense Phase of an Earthquake," Int. Rev. Civ. Eng., vol. 8, no. 1, pp. 1-10, 2017.

[22] M. J. DeJong, “Amplification of Rocking Due to Horizontal Ground Motion,” Earthq. Spectra, vol. 28, no. 4, pp. 1405-1421, 2012.

[23] S. Masanobu, M. Feng, L. Jongheon, and T. Naganuma, "Statistical Analysis of Fragility Curves," $J$. Eng. Mech., vol. 126, no. 12, 2000.

[24] L. Sorrentino, R. Masiani, and L. D. Decanini, "Overturning of rocking rigid bodies under transient ground motions,” Struct. Eng. Mech., vol. 22, no. 3, pp. 293-310, 2006.

[25] E. G. Dimitrakopoulos and T. S. Paraskeva, "Dimensionless fragility curves for rocking response to near-fault excitations," Earthq. Eng. Struct. Dyn., vol. 44, no. 12, pp. 2015-2033, 2015.

[26] H. Krawinkler, J. Osteeras, D. McDonald, and J. Hunt, "Development of Damage Fragility Functions for URM Chimneys and Parapets," in 15th World Conference on Earthquake Engineering, Lisbon, 24th-28th September 2012, 2012.

[27] I. N. Psycharis, M. Fragiadakis, and I. Stefanou, "Seismic reliability assessment of classical columns subjected to near-fault ground motions," Earthq. Eng. \{\&\} Struct. Dyn., vol. 42, no. 14, pp. 2061-2079, 2013.

[28] I. E. Kavvadias, L. K. Vasiliadis, and A. Elenas, "Seismic Response Parametric Study of Ancient Rocking Columns," Int. J. Archit. Herit., vol. 0, no. 0, pp. 1-14.

[29] L. Giresini, M. Fragiacomo, and P. B. Lourenço, "Comparison between rocking analysis and kinematic analysis for the dynamic out-of-plane behavior of masonry walls," Earthq. Eng. Struct. Dyn., vol. 44, no. 13 , pp. 2359-2376, Oct. 2015.

[30] L. Giresini, "Design strategy for the rocking stability of horizontally restrained masonry walls," in COMPDYN 2017 6th ECCOMAS Thematic Conference on Computational Methods in Structural Dynamics and Earthquake Engineering, 2017.

[31] L. Giresini, M. Fragiacomo, and M. Sassu, "Rocking analysis of masonry walls interacting with roofs," Eng. Struct., vol. 116, pp. 107-120, Jun. 2016.

[32] C. Casapulla, L. Giresini, L. U. Argiento, and S. Lagomarsino, "Incremental Static and Dynamic Analyses of the Out-of-Plane Response of a Masonry Church damaged by 2016-2017 Central Italy Earthquakes - Analisi Statiche e Dinamiche Incrementali per la Valutazione della Risposta Fuori Piano della Facciata di una Chiesa," in XVII ANIDIS Conference on "L'ingegneria sismica in Italia," 2017.

[33] L. Sorrentino, O. Alshawa, and L. D. Decanini, "Experimental investigation of energy damping in masonry mechanisms," 2014, vol. 621, pp. 137-142.

[34] A. A. Costa, A. Penna, A. Arêde, and A. Costa, "Simulation of masonry out-of-plane failure modes by multi-body dynamics,” Earthq. Eng. Struct. Dyn., vol. 44, no. 14, pp. 2529-2549, 2015.

[35] DMI, "Decreto del Ministro delle Infrastrutture 14 gennaio 2008. Approvazione delle nuove norme tecniche per le costruzioni." Gazzetta Ufficiale della Repubblica Italiana, n. 29 del 4 febbraio 2008, Supplemento Ordinario n. 30, 2008.

[36] CMIT, "Circolare del Ministro delle Infrastrutture e dei Trasporti 2 febbraio 2009, n. 617, contenente le Istruzioni per l'applicazione delle 'Nuove norme tecniche per le costruzioni' di cui al DM 14 gennaio 
2008." Gazzetta Ufficiale della Repubblica Italiana n. 47 del 26 febbraio 2009, Supplemento Ordinario n. 27, 2009.

[37] J. E. Padgett, B. G. Nielson, and R. DesRoches, "Selection of optimal intensity measures in probabilistic seismic demand models of highway bridge portfolios," Earthq. Eng. Struct. Dyn., vol. 37, no. 5, pp. 711-725, 2008.

[38] E. G. Dimitrakopoulos, N. Makris, and A. J. Kappos, "Dimensional analysis of the earthquake-induced pounding between adjacent structures," Earthq. Eng. Struct. Dyn., vol. 38, no. 7, pp. 867-886, 2009.

[39] P. Fajfar, T. Vidic, and M. Fischinger, "A measure of earthquake motion capacity to damage mediumperiod structures," Soil Dyn. Earthq. Eng., vol. 9, no. 5, pp. 236-242, 1990.

[40] M. D. Trifunac and A. G. Brady, "A study on the duration of strong earthquake ground motion," Bull. Seismol. Soc. Am., vol. 65, no. 3, pp. 581-626, 1975.

[41] E. M. Rathje, F. Faraj, S. Russell, and J. D. Bray, "Empirical Relationships for Frequency Content Parameters of Earthquake Ground Motions," Earthq. Spectra, vol. 20, no. 1, pp. 119-144, 2004.

[42] L. Cabanas, B. Benito, and M. Herraiz, "An approach to the measurement of the potential structural damage of earthquake ground motions," Earthq. Eng. Struct. Dyn., vol. 26, pp. 79-92, 1997.

[43] G. W. Housner, "Spectrum intensities of strong-motion earthquakes," Symp. earthquakes blast Eff. Struct. Los Angeles, CA, 1952.

[44] A. Arias, "A Measure of Earthquake Intensity," in Seismic Design for Nuclear Power Plants, MIT Press, Cambridge, Massachusetts, 1970, pp. 438-483.

[45] J. Pauschke and S. Krishnamurti, "Peak vs. Root-mean-square (rms) acceleration as a response parameter," vol. 4, no. 45, 1982.

[46] C. Scawthorn and W. Chen, Earthquake Engineering Handbook. 2002.

[47] N. Makris and C. J. Black, "Dimensional analysis of bilinear oscillators under pulse-type excitations," J. Eng. Mech., p. 1019, 2004.

[48] L. Luzi, R. Puglia, E. Russo, and O. WG5, "Engineering Strong Motion Database, version 1.0, Istituto Nazionale di Geofisica e Vulcanologia, Observatories \& Research Facilities for European Seismology." 2016.

[49] P. Giovenale, C. A. Cornell, and L. Esteva, "Comparing the adequacy of alternative ground motion intensity measures for the estimation of structural responses," Earthq. Eng. Struct. Dyn., vol. 33, no. 8, pp. 951-979, 2004.

[50] N. Makris, "The role of the rotational inertia on the seismic resistance of free-standing rocking columns and articulated frames," Bull. Seism. Soc. Am., vol. 104, p. 2226, 2014.

[51] L. Giresini, M. Fragiacomo, and P. B. Lourenço, "Comparison between rocking analysis and kinematic analysis for the dynamic out-of-plane behavior of masonry walls," Earthq. Eng. Struct. Dyn., vol. 44, no. 13, pp. 2359-2376, 2015. 